\title{
The cohesin complex and its roles in chromosome biology
}

\author{
Jan-Michael Peters, ${ }^{1}$ Antonio Tedeschi, and Julia Schmitz \\ Research Institute of Molecular Pathology (IMP), A-1030 Vienna, Austria
}

Cohesin is a chromosome-associated multisubunit protein complex that is highly conserved in eukaryotes and has close homologs in bacteria. Cohesin mediates cohesion between replicated sister chromatids and is therefore essential for chromosome segregation in dividing cells. Cohesin is also required for efficient repair of damaged DNA and has important functions in regulating gene expression in both proliferating and post-mitotic cells. Here we discuss how cohesin associates with DNA, how these interactions are controlled during the cell cycle; how binding of cohesin to DNA may mediate sister chromatid cohesion, DNA repair, and gene regulation; and how defects in these processes can lead to human disease.

Eukaryotic cells pass their genomes from one cell generation to the next by first replicating their entire nuclear DNA during $S$ phase and then segregating the resulting sister chromatids from each other later during mitosis or meiosis. The segregation step is carried out with the help of the spindle apparatus, which captures replicated chromosomes in a bipolar fashion during prometaphase. In anaphase, the spindle then moves the sister chromatids into opposite directions so that two genetically identical daughter cells can be formed during cytokinesis. This mechanism of chromosome segregation critically depends on the fact that sister chromatids remain physically connected with each other from the time of their synthesis in S phase until they are separated much later in anaphase. Without this cohesion, sister chromatids could be separated from each other before chromosomes were attached to both poles of the spindle, and an equal distribution of sister chromatids into forming daughter cells would not be possible. Identifying the molecular mechanisms of sister chromatid cohesion is therefore of central importance for understanding the cell division cycle of eukaryotic cells.

During DNA replication, sister chromatids become automatically intertwined with each other at sites where

[Keywords: Cohesin; sister chromatid cohesion; chromosome; mitosis; meiosis; cell cycle]

${ }^{1}$ Corresponding author.

E-MAIL peters@imp.ac.at; FAX 43-1-798-7153.

Article is online at http://www.genesdev.org/cgi/doi/10.1101/gad.1724308. replication forks collide (Sundin and Varshavsky 1980), and these catenations need to be resolved by topoisomerases before sister chromatids can separate in anaphase (DiNardo et al. 1984). It was therefore initially plausible to assume that cohesion may be mediated by DNA catenation (Murray and Szostak 1985). Catenations can indeed mediate some cohesion between sister chromatids if the activity of topoisomerases is experimentally inhibited (Vagnarelli et al. 2004; Toyoda and Yanagida 2006). However, it is unclear whether catenations are also required for sister chromatid cohesion under physiological conditions; i.e., when topoisomerases are active. For entire chromosomes, it has so far been impossible to address this question, because it is presently not possible to create replicated chromosomes in which sister chromatids are not catenated with each other. However, it is now well established that catenation cannot be sufficient for cohesion, because several proteins have been identified that are essential for cohesion that do not appear to regulate catenations between sister chromatids. For yeast minichromosomes, it has furthermore been shown recently that these proteins can mediate cohesion in the absence of catenation (Ivanov and Nasmyth 2007). At least for small circular chromosomes catenation is therefore not essential for cohesion (Koshland and Hartwell 1987; Guacci et al. 1994).

The first proteins that are essential for cohesion were identified by genetic screens for mutants that separate sister chromatids precociously before anaphase, either during meiosis I in the fruit fly Drosophila melanogaster (Davis 1971; Kerrebrock et al. 1992; Miyazaki and OrrWeaver 1992) or during mitosis in the budding yeast Saccharomyces cerevisiae (Guacci et al. 1997; Michaelis et al. 1997). Some of these proteins were also discovered independently in screens for S. cerevisiae, Schizosaccharomyces pombe (fission yeast), and Aspergillus nidulans mutants that are defective in DNA damage repair or in chromosome segregation (Birkenbihl and Subramani 1992; Denison et al. 1993; Strunnikov et al. 1993; Holt and May 1996). Several of these cohesion proteins (Smc1, Smc3, Scc1/Mcd1/Rad21, and Scc3/Irr1) were later shown to be subunits of a protein complex called "cohe$\sin ^{\prime \prime}$ to indicate its essential function in sister chromatid cohesion (Losada et al. 1998; Toth et al. 1999; Sumara et al. 2000). Importantly, cohesin was found to associate 
with chromosomes in budding yeast from late G1 phase until metaphase; i.e., when cohesion exists, but not in anaphase, when cohesion is absent (Michaelis et al. 1997). This observation immediately implied that cohesin itself might be the "glue" that connects sister chromatids. Since then this hypothesis has been supported by numerous observations and experimental tests (for review, see Nasmyth 2005). These include the finding that yeast cohesin mutants that fail to associate with chromosomes cannot establish cohesion (Arumugam et al. 2003; Weitzer et al. 2003; Gruber et al. 2006) and that experimentally induced proteolytic cleavage of cohesin is sufficient to remove cohesin from chromosomes and to abolish cohesion (Gruber et al. 2003). Importantly, one of cohesin's subunits, Scc1, is normally cleaved by the protease separase during metaphase of every cell cycle, and this event is both required and sufficient to release cohesin from chromosomes and to dissolve cohesion between sister chromatids (Uhlmann et al. 1999, 2000). These observations indicate that in budding yeast cohesin itself is part of a structure that mediates cohesion by physically connecting sister chromatids.

The initial genetic screens also identified proteins that were later found to contribute to cohesion more indirectly, either by enabling the association of cohesin with DNA (Scc2) (Michaelis et al. 1997; Toth et al. 1999), by allowing cohesion establishment during $\mathrm{S}$ phase (Ecol/ Ctf7) (Skibbens et al. 1999; Toth et al. 1999), or by preventing the precocious removal of cohesin from chromosomes before anaphase (Mei-S332/Sgo1) (Davis 1971; Kerrebrock et al. 1992; Kitajima et al. 2004; Marston et al. 2004; Rabitsch et al. 2004) (securin) (Funabiki et al. 1996; Yamamoto et al. 1996). For all of these proteins and for cohesin itself, orthologs have been identified in animal cells, and in most cases where this has been tested so far, these proteins have also been found to be required for sister chromatid cohesion. The principal mechanisms through which eukaryotic cells connect their sister chromatids have therefore been highly conserved during evolution, like many other aspects of cell cycle and chromosome biology. However, despite these similarities, there are also surprisingly numerous differences between yeasts and higher eukaryotes in how cohesin is regulated and how it is distributed along DNA.

Although it is well established that cohesin and its regulatory proteins are essential for sister chromatid cohesion, this is not cohesin's only function. Numerous recent studies have shown that cohesin also has important roles in DNA damage pathways and in the regulation of gene expression in both proliferating and postmitotic cells. Many of cohesin's known roles in DNA damage responses can be explained by its function in sister chromatid cohesion, but at least some of cohesin's roles in gene regulation are independent from its cohesion function. It has not been demonstrated yet that cohesin mediates cohesion and gene regulation through the same molecular mechanisms, but it is plausible to assume that cohesin performs both of these functions directly by associating with DNA. In this article we will therefore discuss how interactions between cohesin and
DNA are controlled during the cell cycle in different species, and how these interactions may contribute to cohesion and gene expression, but first we describe the cohesin complex and its cofactors.

\section{Architecture of the cohesin core complex}

In all cases where cohesin complexes have been isolated so far, four core subunits have been identified (Fig. 1A; Table 1). The topology and structure of these subunits has been best characterized in budding yeast (Haering et al. 2002, 2004), but the sequence conservation of these proteins and biochemical and electron microscopic observations imply that cohesin complexes in other species are very similar in their structure (Losada et al. 1998; Sumara et al. 2000; Anderson et al. 2002).

Two cohesin core subunits, Smc1 and Smc3, are members of the "structural maintenance of chromosomes" (SMC) family whose members are large ATPases with an unusual domain organization (Strunnikov et al. 1993; Michaelis et al. 1997). The polypeptide chains of SMC proteins fold back on themselves around a central "hinge" domain, which is followed by an extended 45nm-long anti-parallel coiled-coil structure (Fig. 1A; Melby et al. 1998; Haering et al. 2002; Hirano and Hirano 2002). At the other end of the coiled-coil domain a globular ATPase "head" is formed by N- and C-terminal sequences. Within cohesin, the hinge domains of Smcl and Smc3 bind tightly to each other, whereas the ATPase heads of both proteins are physically connected by the Scc1 subunit (Haering et al. 2002). Scc1 is a member of a protein family, called kleisins (after the greek word for bridge) because these subunits "bridge" the ATPase heads in different SMC complexes (Schleiffer et al. 2003).
A

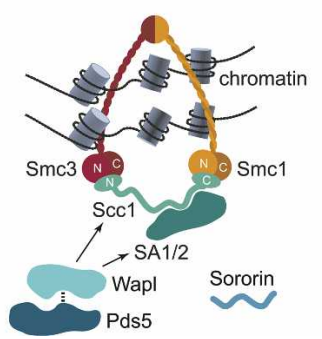

B

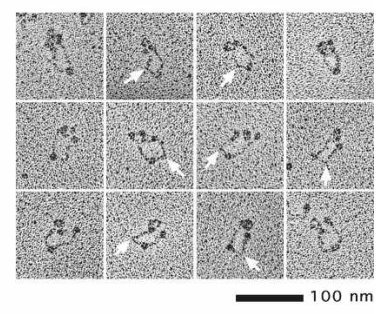

Figure 1. The cohesin complex. (A) Model for the architecture of the cohesin complex on chromatin. In somatic vertebrate cells, the cohesin core complex consists of Smc1, Smc3, Scc1, and either SA1 or SA2. Association of Wapl with the core complex depends on Scc1 and SA1 (indicated by arrows), and there is evidence that Wapl directly interacts with Pds5 (dashed line) (Kueng et al. 2006). How sororin interacts with cohesin is unknown. According to the "ring" model, cohesin mediates sister chromatid cohesion by topological embrace, and it has been suggested that the tripartite ring formed by Smc1, Smc3, and Sccl could encircle two 10-nm chromatin fibers. See the text for details. (B) Examples of electron micrographs of human cohesin complexes. Arrows indicate a kink that is often observed at a fixed position in one of the two coiled-coil arms. Originally published in Anderson et al. (2002) in the Journal of Cell Biology (c) 2002). 
Table 1. Cohesin subunits and associated proteins

\begin{tabular}{|c|c|c|c|c|c|c|c|}
\hline $\begin{array}{l}\text { Generic } \\
\text { human } \\
\text { name }\end{array}$ & $\begin{array}{c}\text { Predicted/apparent } \\
\text { mass } \\
\text { (kilodaltons) }\end{array}$ & H.s. ${ }^{a}$ & D.m. ${ }^{b}$ & S.p..$^{c}$ & S.c. ${ }^{d}$ & Structural motifs & Function \\
\hline Smc1 & $143 / 160$ & SMC1A & SMC1 & psm1 & SMC1 & $\begin{array}{l}\text { Hinge } \\
\text { Coiled-coil } \\
\text { ATPase "head" }\end{array}$ & Cohesin subunit \\
\hline Smc1 $\beta$ & 144 & SMC1B & & & & $\begin{array}{l}\text { Hinge } \\
\text { Coiled-coil } \\
\text { ATPase "head" }\end{array}$ & Cohesin subunit (meiosis) \\
\hline Smc3 & 140 & SMC3 & Cap & psm3 & SMC3 & $\begin{array}{l}\text { Hinge } \\
\text { Coiled-coil } \\
\text { ATPase "head" }\end{array}$ & Cohesin subunit \\
\hline Scc1 & $72 / 120$ & RAD21 & $\operatorname{Rad} 21$ & $\operatorname{rad} 21$ & MCD1 & Low-complexity region & Cohesin subunit \\
\hline Rec8 & 63 & REC8 & $c(2) M$ & rec8 & REC8 & Low-complexity region & Cohesin subunit (meiosis) \\
\hline SA-1 & 145 & STAG1 & SA & psc3 & $\operatorname{IRR} 1$ & & Cohesin subunit \\
\hline SA-2 & 138 & STAG2 & SA2 & & & & \\
\hline SA-3 & 139 & STAG3 & - & rec11 & & & Cohesin subunit (meiosis) \\
\hline Pds5A & 151 & PDS5A & pds5 & pds5 & PDS5 & HEAT repeats & Maintenance of cohesion \\
\hline Pds5B & 165 & PDS5B & & & & HEAT repeats & \\
\hline Wapl & $140 / 180$ & WAPAL & wapl & wap1 & RAD61/WPL1 & $\begin{array}{l}\text { Armadillo repeats } \\
\text { HEAT repeats }\end{array}$ & Cohesin dissociation \\
\hline Sororin & $28 / 35$ & CDCA5 & - & - & - & KEN box & $\begin{array}{l}\text { Establishment or } \\
\text { maintenance of } \\
\text { cohesion }\end{array}$ \\
\hline
\end{tabular}

a(H.s.) Homo sapiens. Gene nomenclature according to HUGO Gene Nomenclature Committee (http://www.genenames.org).

${ }^{\mathrm{b}}(D . m$.) Drosophila melanogaster. Gene nomenclature according to FlyBase (http://flybase.bio.indiana.edu//).

c(S.p.) Schizosaccharomyces pombe. Gene nomenclature according to Schizosaccharomyces pombe GeneDB (http://www.genedb.org/ genedb/pombe/index.jsp).

d(S. c.) Saccharomyces cerevisiae. Gene nomenclature according to Saccharomyces Genome Database (http://www.yeastgenome.org).

In the case of Scc1, the $\mathrm{N}$ terminus binds to the ATPase domain of Smc3 and the C terminus binds to Smc1. Because Smc1 and Smc3 bind to each other at both of their ends, at one end via their hinge domains and at the other with the help of Scc1 via their ATPase domains, a ringlike structure with an outer diameter of $\sim 50 \mathrm{~nm}$ is formed (Haering et al. 2002). The existence of this peculiar subunit arrangement is also well supported by electron microscopic images of purified vertebrate cohesin complexes (Fig. 1B; Anderson et al. 2002) and by crystal structures of subcomplexes of cohesin or related SMC complexes (Haering et al. 2002, 2004). Scc1 is further associated with the fourth subunit of the cohesin core complex, called Scc3, whose structure has not been determined yet. In somatic vertebrate cells, two closely related Scc3 homologs exist, called stromalin antigens 1 and 2 (SA1 and SA2). Both proteins are subunits of cohesin complexes that contain either SA1 or SA2, but never both (Losada et al. 2000; Sumara et al. 2000). In somatic cells, cohesin ${ }^{\mathrm{SA} 2}$ is about threefold more abundant than cohesin ${ }^{\text {SA1 }}$, whereas Xenopus eggs contain 10 times more cohesin ${ }^{\mathrm{SA} 1}$ than cohesin ${ }^{\mathrm{SA} 2}$. The functional difference between cohesin ${ }^{\mathrm{SA} 1}$ and $\operatorname{cohesin}^{\mathrm{SA} 2}$ is yet to be clarified.

\section{Cohesin-associated proteins}

In addition to these "core" components, three other proteins have been identified that are associated with cohe- sin. One of these proteins is Pds5 (Denison et al. 1993; van Heemst et al. 1999), whose sequence has been well conserved during evolution, and is characterized by numerous HEAT repeats (Panizza et al. 2000) that are known to function as protein interaction domains in other proteins. Vertebrate cells contain two Pds5 homologs, Pds5A and Pds5B, which can both associate with cohesin $^{\text {SA1 }}$ and cohesin ${ }^{\text {SA2 }}$ (Sumara et al. 2000; Losada et al. 2005). Somatic vertebrate cells therefore contain at least four distinct types of cohesin, which contain either SA1 or SA2, and either Pds5A or Pds5B. In yeasts, worms, and Drosophila, Pds5 is essential for cohesion (Hartman et al. 2000; Panizza et al. 2000; Tanaka et al. 2001; Stead et al. 2003; Wang et al. 2003; Dorsett et al. 2005), whereas depletion of Pds5A or Pds5B from vertebrate cells was found to have only minor (Losada et al. 2005) or no effects on cohesion (Zhang et al. 2007). It is therefore possible that Pds5A and Pds5B are redundant in their functions in sister chromatid cohesion.

In vertebrates, cohesin complexes are also associated with Wapl (Gandhi et al. 2006; Kueng et al. 2006), a protein that was initially discovered in Drosophila, where it has been implicated in heterochromatin formation (Perrimon et al. 1985; Verni et al. 2000). Like Pds5, Wapl contains repetitive sequences that may mediate proteinprotein interactions. Contrary to the situation with Pds5, the sequence of Wapl is only poorly conserved in fungi, but both $S$. cerevisiae and $S$. pombe contain a distantly related protein, which is called Rad61 in budding 
yeast (Kueng et al. 2006). Recent work has shown that Rad61 also associates with cohesin in S. cerevisiae (BenShahar et al. 2008), implying that Rad61 represents the fungal ortholog of Wapl. Rad61 is therefore now also called Wpl1. In vertebrates, the binding of Wapl to cohesin depends on the presence of Scc1 and SA1/SA2 (Kueng et al. 2006), and recombinant Wapl forms a complex with Scc1 and SA1 (Gandhi et al. 2006). In human cell lysates, Wapl is further present in a distinct subcomplex with Pds5A (Kueng et al. 2006). It is therefore possible that Wapl and Pds5 form a heterodimer that interacts with cohesin by associating with SA1/SA2 or Scc1. Unlike cohesin core subunits, Wapl is not required for sister chromatid cohesion in vertebrate cells. Instead, Wapl is needed to remove cohesin complexes from chromatin (Gandhi et al. 2006; Kueng et al. 2006). A similar function has recently been described for Wpll in $S$. pombe (Bernard et al. 2008). Surprisingly, a different situation has been observed in Drosophila and budding yeast, where Wapl/Rad61 inactivation causes mild cohesion defects, in the case of Drosophila specifically in heterochromatic regions (Verni et al. 2000; Warren et al. 2004). The molecular basis of these phenotypic differences is not yet understood.

A third cohesin interactor is called sororin, a small protein that was initially discovered as a substrate of the ubiquitin ligase anaphase-promoting complex/cyclosome (APC/C) (Rankin et al. 2005). Like cohesin, sororin is essential for sister chromatid cohesion (Rankin et al. 2005; Diaz-Martinez et al. 2007b; Schmitz et al. 2007). However, in contrast to Pds5, Wapl, and cohesin core subunits, sororin has only been identified in vertebrates so far and its sequence is much less well conserved than that of other cohesion proteins, even among vertebrates. How sororin interacts with cohesin is not yet known.

\section{Meiotic cohesin complexes}

Similar, yet distinct cohesin complexes exist in meiotic cells. These cells undergo two rounds of chromosome segregation without intervening DNA replication, so that haploid germ cells can be generated from diploid progenitor cells. Meiosis I differs fundamentally from mitosis, because homologous chromosomes are separated from each other during meiosis I, whereas sister chromatids are only separated in meiosis II (for review, see Petronczki et al. 2003; Marston and Amon 2004; Watanabe 2004). This unusual process depends on the ability of meiotic cells to form "bivalents" by pairing homologous chromosomes, and on the ability to co-orient the kinetochores of sister chromatids in these bivalents. As a result, both sister kinetochores attach to the same spindle pole in meiosis I. Importantly, at the first metaphase-anaphase transition, cohesin is only removed from chromosome arms, whereas cohesin maintains cohesion at centromeres until metaphase of meiosis II. This stepwise removal of cohesin depends on the substitution of the kleisin subunit Scc1 by a meiosis-specific paralog called Rec8 (Klein et al. 1999; Watanabe and Nurse 1999). Meiotic isoforms of other cohesin core sub- units also exist (Table 1). In mammals, Smc1 and SA1/ SA2 can be replaced by Smc1 $\beta$ and STAG3, respectively (Pezzi et al. 2000; Prieto et al. 2001; Revenkova et al. 2001, 2004), and in fission yeast the Scc3 ortholog Psc3 coexists with the related Rec11 protein in meiotic cells (Kitajima et al. 2003a).

Rec8 orthologs have been characterized in many species (Pasierbek et al. 2001; Xu et al. 2005; for review, see Nasmyth and Haering 2005), including Drosophila, where a Rec8-related protein, called $\mathrm{C}(2) \mathrm{M}$ is also expressed during meiosis (Heidmann et al. 2004). However, it remains to be clarified whether $\mathrm{C}(2) \mathrm{M}$ has the same fuctions as Rec8, because inactivation of $\mathrm{C}(2) \mathrm{M}$ causes less severe defects than Rec 8 deletion in meiotic yeast cells. This could be due to partial redundancy between $\mathrm{C}(2) \mathrm{M}$ and Scc1, which in many organisms is also expressed at low levels in meiosis (discussed in Nasmyth 2005). Alternatively, more distantly related proteins might functionally replace Rec8. This has been proposed for the ORD protein, which has more functional similarities with Rec8 than C(2)M, although ORD differs in sequence from kleisins (Miyazaki and Orr-Weaver 1992; Bickel et al. 1996; Khetani and Bickel 2007).

\section{Cohesin-related complexes}

Smc1 and Smc3 are not only part of cohesin, but have also been identified as subunits of a recombination complex that has been purified from bovine thymic cells (Jessberger et al. 1996; Stursberg et al. 1999). This complex is called RC-1 and contains in addition DNA polymerase $\varepsilon$, DNA ligase III, and an endonuclease. Proteins closely related to Smc1 and Smc3 are also found in other protein complexes. Interestingly, all of these interact with chromatin and are required for various aspects of chromosome structure and segregation. Eukaryotic cells contain four additional SMC proteins (for review, see Nasmyth and Haering 2005). Smc2 and Smc4 form heterodimers that are part of two distinct complexes, called condensin I and condensin II. Each of these contains three unique non-SMC subunits, a kleisin subunit, and two HEAT repeat proteins. This situation is remarkably similar to the composition of cohesin complexes that are associated with Wapl and Pds5 proteins, which also contain HEAT repeats. However, condensin complexes have been implicated mainly in chromosome condensation and segregation. Smc5 and Smc6 assemble into a separate complex together with several non-SMC proteins. These complexes are also required for chromosome segregation and DNA damage repair.

Remarkably, SMC complexes also exist in bacteria, where a single SMC protein assembles into a homodimer that can associate with a kleisin subunit (Britton et al. 1998; Melby et al. 1998; Moriya et al. 1998; Mascarenhas et al. 2002; Schleiffer et al. 2003). Also, these proteins have important functions in structuring DNA in the nucleoids of bacteria and in bacterial chromosome segregation. The finding that SMC complexes exist in prokaryotes implies that these proteins have existed before histones, and the mechanism through which SMC pro- 
teins structure DNA must therefore be much more ancient than organization of DNA by nucleosomes.

Finally, eukaryotic cells also contain a protein that is more distantly related to SMCs, called Rad50, which functions in DNA double-strand break (DSB) repair. Like SMC proteins, Rad50 contains ABC-type ATPase domains, a long anti-parallel coiled-coil region, and forms homo-dimers. However, the structure of Rad50's hinge domain is very different from the hinge domain that is found in SMC proteins, implying that Rad50 might interact with DNA differently than cohesin (Hopfner et al. 2000, 2002).

\section{Evidence that cohesin is required for sister chromatid cohesion in animal cells}

In budding yeast the genetic screens for cohesion mutants established immediately that cohesin genes are essential for sister chromatid cohesion. In vertebrate cells, however, the role of cohesin in sister chromatid cohesion remained initially less clear, in part because depletion of cohesin from Xenopus egg extracts causes only mild cohesion defects (Losada et al. 1998), and in part because most cohesin complexes are removed from chromosomes already during prophase; i.e., before cohesion is dissolved at the metaphase-anaphase transition (Fig. 2; Losada et al. 1998; Sumara et al. 2000). This situation is very different from the situation in budding yeast, where cohesin inactivation causes strong cohesion defects and where cohesin removal from chromosomes coincides well with anaphase onset (Guacci et al. 1997; Michaelis

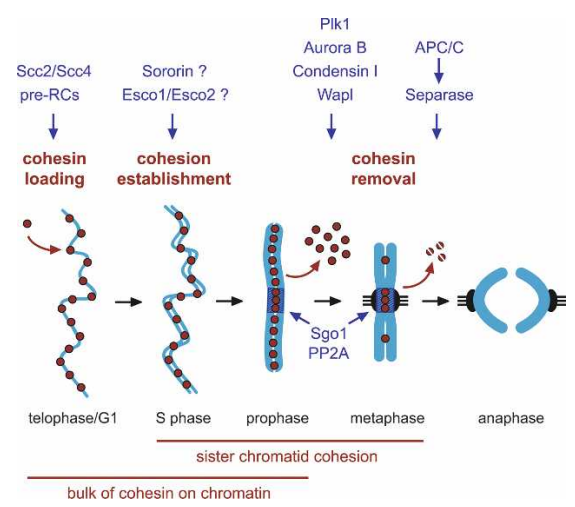

Figure 2. Regulation of sister chromatid cohesion during the vertebrate cell cycle. Loading of cohesin onto chromatin occurs during telophase and G1 and requires the cohesin loading factors Scc2 and Scc4. In Xenopus egg extracts, cohesin loading also depends on the assembly of pre-RCs on chromatin. During $S$ phase, cohesion between sister chromatids is established, and this process may depend on sororin, Esco1, and Esco2. During prophase, the bulk of cohesin dissociates from chromatin, and this removal is regulated by Plk1, Aurora B kinase, condensin I, and Wapl. Cohesin at centromeres is protected by Sgol and PP2A. At the metaphase-to-anaphase transition, separase is activated by the APC/C and cleaves centromeric cohesin as well as residual cohesin on chromosome arms, enabling sister chromatid separation. See the text for details. et al. 1997). In particular, the finding that vertebrate cohesin is removed from chromosomes by a prophase pathway initially raised some doubts about whether cohesin maintains cohesion during early mitosis in vertebrate cells. However, since then it has been shown that small amounts of cohesin persist on mammalian chromosomes until metaphase (Hoque and Ishikawa 2000; Waizenegger et al. 2000; Hauf et al. 2001; Gerlich et al. 2006). These complexes represent only about $10 \%$ of all cohesin complexes, and in microscopy experiments they can only be detected reliably by stable expression of epitopetagged cohesin subunits. Importantly, these complexes are enriched at centromeres, the sites on mitotic chromosomes where cohesion remains particularly tight until metaphase, and this subpopulation of cohesin is removed from chromosomes immediately before sister chromatids separate, consistent with a role of these complexes in cohesion (Waizenegger et al. 2000; Gerlich et al. 2006). Localization of cohesin in Xenopus and Drosophila cells (Losada et al. 2000; Warren et al. 2000; Valdeolmillos et al. 2004) and of the Pds5 ortholog Spo76 in the fungus Sordaria (van Heemst et al. 1999) indicate that a similar situation may exist in many other organisms.

The notion that cohesin is also essential for sister chromatid cohesion in vertebrates and in other animals has in the meantime been supported by numerous observations. If cohesin is depleted from cultured Drosophila, chicken, or mammalian cells, precociously separated sister chromatids are observed in cells in prometaphase (Sonoda et al. 2001; Vass et al. 2003; Toyoda and Yanagida 2006; Watrin et al. 2006). A similar situation is seen when dominant-negative mutants of Scc1 are expressed in mammalian cultured cells (Hoque and Ishikawa 2002). These phenotypes are presumably caused by cohesion defects that occurred during $\mathrm{S}$ and G2 phase, because DNA fluorescence in situ hybridization (FISH) experiments revealed that cohesin depletion leads to increased distances between sister chromatids already during G2 phase (Sonoda et al. 2001; Schmitz et al. 2007). However, it is possible that cohesion defects become particularly obvious during early mitosis, because the prophase pathway removes the bulk of cohesin from chromosomes at this time and may thus help to uncover cohesion phenotypes in cells from which cohesin was only partially depleted. The notion that cohesin has an important function in cohesion is also supported by experiments in which the prophase pathway of cohesin dissociation has been manipulated. If protection of cohesin from this pathway is lost following depletion of the shugoshin 1 (Sgo1) protein, cohesin dissociates from chromosomes precociously and cohesion is abrogated in prometaphase (Salic et al. 2004; Tang et al. 2004; Kitajima et al. 2005; McGuinness et al. 2005). Conversely, inhibition of the prophase pathway leads to the formation of mitotic chromosomes with unusually high amounts of bound cohesin and with sister chromatids that are much more tightly connected with each other than normally (Losada et al. 2002; Gimenez-Abian et al. 2004; Hauf et al. 2005; Gandhi et al. 2006; Kueng et al. 
2006). These observations indicate that cohesin is important for sister chromatid cohesion, not only in yeast, but also in higher eukaryotic cells, despite the fact that only very small amounts of cohesin remain on chromosomes in early mitosis.

\section{How does cohesin interact with DNA?}

It has long been assumed that cohesin mediates sister chromatid cohesion by directly interacting with the DNA molecules of sister chromatids. Initial models suggested that the ATPase heads of Smc1 and Smc3 may directly contact DNA (Nasmyth et al. 2000), and consistent with this possibility it has been observed that recombinant fragments of Smc3 and purified cohesin core complexes can bind to DNA in vitro (Akhmedov et al. 1999; Losada and Hirano 2001; Sakai et al. 2003; Kagansky et al. 2004). However, unlike loading of cohesin onto DNA in vivo (see below), these interactions are independent of ATP and the resulting interactions seem to be of low affinity. It is therefore unknown to what degree these in vitro interactions reflect how cohesin associates with DNA in vivo. Importantly, it has furthermore been observed that proteolytic cleavage of either Scc1 or Smc3 destroys binding of cohesin to chromatin in vivo (Gruber et al. 2003), and truncated cohesin complexes lacking the hinge domain can likewise not associate with chromatin (Weitzer et al. 2003). These observations indicate that the ATPase heads of cohesin are not sufficient for DNA binding.

Because the Smc1, Smc3, and Scc1 subunits of cohesin bind to each other in a way that creates a tripartite structure, a more recent model proposes that cohesin mediates cohesion by embracing the replicated DNA molecules as a ring (Haering et al. 2002; Gruber et al. 2003). According to this "ring" model, cohesin would not have to contact DNA directly, but would instead connect sister chromatids in a topological fashion (Fig. 1A). This hypothesis is attractive because it can explain well why proteolytic cleavage of either Scc1 or Smc3 causes dissociation of cohesin from DNA and results in loss of cohesion (Uhlmann et al. 2000; Gruber et al. 2003), and why in yeast cells cohesin binds to DNA in a sequence independent manner (see below). The ring model is also supported by a number of additional experimental observations: Cohesin can dissociate from circular minichromosomes if these are linearized with restriction enzymes (Ivanov and Nasmyth 2005), and also in this case, cohesion between replicated minichromosomes is lost (Ivanov and Nasmyth 2007). If cohesin subunits are fused to each other by genetic manipulation, cohesin cannot associate with DNA any longer, consistent with the possibility that cohesin rings have to be opened to be loaded onto DNA (Gruber et al. 2006). Finally, if cohesin is loaded onto DNA and cohesin subunits are then covalently linked to each other via chemical cross-linking in vitro, cohesin-DNA interactions, and cohesion between minichromosomes become resistant even to denaturing conditions, further supporting the embrace model (Haering et al. 2008).
Other models of cohesin-DNA interactions have also been proposed. These models posit that two cohesin complexes form a symmetric dimeric structure that physically connects the sister chromatids (the "snap" or "handcuff" model), or that cohesin assembles into larger oligomers on DNA (the "bracelet" model) (C.E. Huang et al. 2005). These models are difficult to test due to the inherent problems of studying proteins when they are bound to chromatin, but so far no evidence for oligomerization of cohesin has been obtained (Haering et al. 2002, 2008; Gruber et al. 2003; Weitzer et al. 2003).

\section{Cohesin-binding sites in eukaroytic genomes}

\section{Chromosome arm regions}

Cohesin-binding sites were first identified by chromatin immunoprecipitation (ChIP) techniques in the budding yeast genome. These experiments revealed that cohesin binds to discrete cohesin attachment regions (CARs) on chromosome arms and to a larger domain surrounding centromeres (Blat and Kleckner 1999; Megee et al. 1999; Tanaka et al. 1999). The arm sites are $\sim 0.8 \mathrm{~kb}$ in size and are on average $10 \mathrm{~kb}$ apart from each other (Laloraya et al. 2000). No specific sequence elements have been identified in CARs, but they have an increased A/T content (Blat and Kleckner 1999), and $>80 \%$ of all CARs are found in intergenic regions at sites of convergent transcription (Glynn et al. 2004; Lengronne et al. 2004; Lindroos et al. 2006). Interestingly, microscopic observations and ChIP experiments indicate that the distribution of cohesin is different from the DNA-binding pattern of Scc2 (Ciosk et al. 2000; Lengronne et al. 2004), a protein that is required to load cohesin onto DNA (see below). An interesting implication of these results is that either cohesin or Scc2 might be relocated to different sites on DNA once the loading reaction has occurred. Based on ChIP experiments, it has indeed been suggested that cohesin is initially loaded at Scc2 sites, but is then relocated by the RNA polymerase II transcription machinery to sites of convergent transcription (Lengronne et al. 2004; Bausch et al. 2007). Whether cohesin rings can slide along DNA during this relocation process, or if they have to be removed from DNA and subsequently reloaded, is presently unknown.

In animal cells, discrete cohesin-binding sites also have been recently identified in the nonrepetitive parts of genomes, but these sites differ in several ways from CARs in budding yeast. In Drosophila, cohesin preferentially binds to transcribed regions, and contrary to the situation in budding yeast, it has been suggested that RNA polymerase II-mediated transcription facilitates cohesin binding, perhaps by unfolding chromatin (Misulovin et al. 2008). Also, in contrast to the situation in budding yeast, the Drosophila Scc2 ortholog Nipped-B has been reported to colocalize with cohesin on chromosomes (Misulovin et al. 2008).

In mammalian cells, Scc2-binding sites have not yet been identified, and for cohesin, yet a different binding pattern than in Drosophila has been observed (Parelho et 
al. 2008; Wendt et al. 2008). In human cells, about half of all identified cohesin sites are present in intergenic regions, but many sites are also found in introns (35\%) and in regions that are either directly upstream of or downstream from genes (13\%) (Wendt et al. 2008). Compared with the overall frequency of these sequences in the human genome, the cohesin-binding sites adjacent to genes are enriched twofold to threefold, consistent with the possibility that these sites have some role in gene regulation (see below). There is no obvious enrichment of cohesin at sites of convergent transcription, perhaps because intergenic regions are much larger in vertebrate genomes (Parelho et al. 2008; Wendt et al. 2008). Unlike in yeast, there is also no evidence that transcription alters the pattern of cohesin binding to active genes (Parelho et al. 2008; Wendt et al. 2008). These observations indicate that in vertebrates the transcription machinery does not permanently remove cohesin from DNA, although it is possible that cohesin has to be transiently dissociated when RNA polymerases move along DNA.

Interestingly, most cohesin sites that have been identified by ChIP-chip in mammalian cells are also bound by a zinc finger protein, called CCCTC-binding factor (CTCF) (Parelho et al. 2008; Rubio et al. 2008; Stedman et al. 2008; Wendt et al. 2008). If CTCF is depleted, cohesin fails to accumulate at CTCF sites, although cohesin can still associate with DNA and establish sister chromatid cohesion (Parelho et al. 2008; Wendt et al. 2008). Conversely, cohesin is not essential for recruiting CTCF to its binding sites. CTCF may therefore position cohesin at specific sites to which CTCF binds via its zinc finger domain. How CTCF recruits cohesin to these sites is unknown. It has been reported that CTCF can be coimmunoprecipitated with cohesin (Stedman et al. 2008), but such interactions have not been detected in another study (Wendt et al. 2008). It is therefore possible that cohesin interacts with CTCF only transiently, or only when bound to DNA. Alternatively, CTCF might induce the formation of DNA structures that indirectly lead to accumulation of cohesin at these sites. It is presently unknown where cohesin binds to DNA in the absence of CTCF, perhaps because cohesin is more equally distributed along DNA under these conditions and may therefore be less easy to detect in ChIP-chip assays. Likewise, it remains to be clarified whether, under normal conditions, cohesin is only present at CTCF sites, or whether smaller amounts of cohesin are also present in other regions of mammalian genomes.

\section{Centromeres}

In all species studied so far, cohesin also binds to centromeric DNA. Cohesin binding at these sites is thought to be particularly important because centromeres are directly exposed to spindle pulling forces in mitosis. Sister centromeres must resist these forces until metaphase, for which sister chromatid cohesion is essential (Tanaka et al. 2000; Eckert et al. 2007). In addition, cohesion might help to orient sister kinetochores toward opposite spindle poles, a geometry that facilitates biorientation of chromosomes on the spindle. In budding yeast, where centromeres are only about 120 bp short (Clarke and Carbon 1985), cohesin binds to a large pericentric domain that extends $>20-50 \mathrm{~kb}$ (Weber et al. 2004; Kiburz et al. 2005). The enrichment of cohesin at centromeres depends on proteins that are essential for kinetochore assembly, such as Mif2 and the H3-related core histone Cse4, which are orthologs of Cenp-C and Cenp-A in mammals, respectively (Tanaka et al. 1999). Centromeric DNA is also required for the binding of cohesin to pericentric domains (Megee et al. 1999; Weber et al. 2004). In budding yeast, centromeres therefore function as "enhancers" of cohesin binding (Weber et al. 2004; Kiburz et al. 2005). Despite the strong enrichment of cohesin at these sites, sister centromeres can transiently separate far away from each other during metaphase (Goshima and Yanagida 2000; Tanaka et al. 2000; He et al. 2000). This "breathing" of centromeres coincides with loss of cohesin from centromeric DNA, presumably due to dissociation of cohesin complexes that had established cohesion (Eckert et al. 2007; Ocampo-Hafalla et al. 2007). When sister centromeres reassociate, cohesin levels on centromeric DNA increase again, possibly due to reloading of cohesin.

In fission yeast, cohesin is also enriched at centromeres, although the structure of centromeres is very different in this species than in budding yeast. Fission yeast centromeres are composed of a central core that is surrounded by large inverted repeats in which cohesin is enriched (Tomonaga et al. 2000; Watanabe et al. 2001). The $S$. pombe ortholog of heterochromatin protein 1 (HP1), Swi6, is also located in the outer repeats (Nakayama et al. 2000; Partridge et al. 2000). Swi6 is recruited to these regions by the methyltransferase Clr4, which creates binding sites for Swi6 by methylating histone H3 on lysine residue 9 (Bannister et al. 2001; Nakayama et al. 2001). Interestingly, both Swi6 and Clr4 are needed for enrichment of cohesin in the outer repeats of fission yeast centromeres (Bernard et al. 2001; Nonaka et al. 2002). Following chemical cross-linking, physical interactions can be detected between Swi6 and the cohesin subunit Psc3 (an ortholog of budding yeast Scc3), indicating that Swi6 may have a direct role in recruiting or maintaining cohesin in pericentric heterochromatin (Nonaka et al. 2002). In addition, the protein kinase Hsk1-Dfp1, an ortholog of Cdc7 in vertebrates, is also needed to enrich cohesin at the outer repeats of fission yeast centromeres (Bailis et al. 2003).

In animal cells, centromeres are composed of major and minor "satellite" repeat sequences. The minor satellites form centric chromatin on which kinetochores assemble, whereas major satellites form pericentric heterochromatin. Similar to the situation in fission yeast, the $\alpha$ isoform of HP1 is specifically enriched in major satellite repeats (Guenatri et al. 2004) to which HP1 $\alpha$ is recruited by a Clr4-related histone methyltransferase, called Suv39h (Rea et al. 2000; Bannister et al. 2001). In ChIP experiments, cohesin binding to major satellite repeats can be detected (Koch et al. 2007), but it is un- 
known whether cohesin binding is restricted to these pericentric regions, and whether this binding is enriched relative to cohesin binding in arm regions. In immunofluorescence microscopy experiments, cohesin can be seen enriched at centromeres of mitotic chromosomes, but this enrichment is, at least to a large part, due to selective removal of cohesin from chromosome arms by the prophase pathway (see below). Controversial results have been obtained concerning the role of HP1 proteins in regulating the levels of cohesin at centromeres in animal cells. Koch et al. (2007) found that neither the association of cohesin with major satellite repeats in interphase nor the enrichment of cohesin on mitotic centromeres is detectably reduced in cells that are lacking Suv39h, and in which HP1 proteins can therefore not be recruited properly to pericentric heterochromatin. In contrast, a reduction in cohesin and partial cohesion defects were observed in mitotic human cells in which HP1 $\alpha$ was depleted (Yamagishi et al. 2008), or in which dominant-negative forms of HP1 proteins were overexpressed (Inoue et al. 2008). A partial reduction in cohesin at centromeres has also been seen in $\mathrm{Su}(\mathrm{var}) 3-9$ mutants in Drosophila (Peng and Karpen 2007). It is possible that centromeric enrichment of HP1 is one of several partially redundant mechanisms by which cohesin is recruited to centromeres in animal cells. This notion would also be consistent with the situation in budding yeast, where orthologs of Clr4/Suv39h and Swi6/HP1 do not exist and where, therefore, cohesin must be enriched at centromeres by an HP1-independent mechanism.

\section{Transcriptionally silent chromatin}

Although Swi6/HP1 proteins do not exist in budding yeast, there are regions in the $S$. cerevisiae genome that can be transcriptionally silenced, such as mating-type loci and subtelomeric repeats. In both of these regions, cohesin-binding sites have been identified (Laloraya et al. 2000). The role of some of these sites has recently been studied in detail by using an elegant approach with which silent chromatin at the HMR locus can be excised from the arm of chromosome III as a piece of circular DNA (C.R. Chang et al. 2005; Dubey and Gartenberg 2007). This system has enabled the analysis of cohesion specifically at the HMR locus, without interfering effects of neighboring chromosomal arm regions. These studies revealed that cohesion at the HMR locus depends not only on cohesin but also on the Sir2-4 silencing complex, which is dispensable for cohesion at centromeres (C.R. Chang et al. 2005). At the HMR locus the establishment of sister chromatid cohesion, but not its maintenance, also requires the presence of an adjacent tRNA gene and recruitment of RNA polymerase III to this gene (Dubey and Gartenberg 2007). How this tRNA gene promotes establishment of cohesion during DNA replication is not known, but interestingly, the tRNA gene is specifically required for recruitment of cohesin to only one of several cohesin-binding sites in the HMR locus. A possible implication of these findings is that functionally different cohesin-binding sites may exist in the
HMR locus, some that participate in cohesion, and others that do not, or that are at least not sufficient to generate cohesion (Dubey and Gartenberg 2007).

These studies revealed further that the RSC chromatin remodeling complex is required for cohesion at the HMR locus (C.R. Chang et al. 2005). RSC has also been implicated in cohesion functions at other loci (Baetz et al. 2004; Huang et al. 2004; C.R. Chang et al. 2005) and the related SNFH2 complex has been reported to load cohesin onto repetitive Alu sequences in human cells (Hakimi et al. 2002), but the precise role of RSC in cohesion remains poorly understood and controversial (discussed in Riedel et al. 2004).

\section{Loading of cohesin onto DNA}

In budding yeast, cohesin associates with DNA at the end of G1 phase (Guacci et al. 1997; Michaelis et al. 1997), whereas in vertebrate cells the loading of cohesin onto DNA is initiated already in telophase following reformation of the nuclear envelope (Losada et al. 1998; Darwiche et al. 1999; Sumara et al. 2000; Gerlich et al. 2006). This difference may be related to differences in mitotic regulation of cohesin in different organisms. In budding yeast, most Sccl is cleaved by separase in metaphase (Uhlmann et al. 1999), and cohesin can therefore only accumulate once separase has been inactivated. In vertebrates, on the other hand, most cohesin is removed from chromosomes by the prophase pathway without Scc1 cleavage, and cohesin is therefore available for binding to DNA at the end of mitosis.

In all organisms studied so far, loading of cohesin onto DNA depends on a complex of two proteins, called Scc2 and Scc4 (Furuya et al. 1998; Ciosk et al. 2000; Gillespie and Hirano 2004; Rollins et al. 2004; Takahashi et al. 2004; Bernard et al. 2006; Seitan et al. 2006; Watrin et al. 2006). For yeast cohesin it has further been shown that cohesin binding to DNA also depends on the ability of Smc1 and Smc3 to bind and hydrolyze ATP (Arumugam et al. 2003; Weitzer et al. 2003), and it has been proposed that the hinge domain of Smcl and Smc3 has to open to allow passage of the DNA into the cohesin ring (Gruber et al. 2006). Also, biochemical experiments using bacterial SMC proteins suggest that the hinge domain has an important role in the DNA-binding reaction (Hirano and Hirano 2006). It is therefore conceivable that the Scc2/ Scc4 complex promotes loading of cohesin onto DNA by stimulating its ATPase activity, which might in turn allow transient opening of the hinge domain. How ATP hydrolysis might influence interactions between the hinge domains is a mystery, but interestingly, experiments with $S$. cerevisiae cohesin have shown that the ATPase and hinge domains of Smc1/Smc3 can interact with each other (Mc Intyre et al. 2007). Similar interactions have been suggested for condensin based on atomic force microscopy experiments (Yoshimura et al. 2002). It is further interesting to note that the ATPase domains of Smc1 and Smc3 are related to ABC transporters, whose ATPase domains regulate opening of a transmembrane channel. These changes are thought to be mediated by 
ATP hydrolysis, which in turn influences dimerization between two ATPase domains (Chen et al. 2003; Venter et al. 2003). It is therefore plausible to think that similar conformational changes in Smc1 and Smc3 may be required for loading of cohesin onto DNA.

A direct role for Scc2/Scc4 in cohesin loading is supported by the observation that a small fraction of cohesin is associated with Scc2/Scc4 in S. cerevisiae, Drosophila, and in Xenopus egg extracts (Toth et al. 1999; Gause et al. 2008; Takahashi et al. 2008). Experiments with Xenopus cohesin indicate that the loading of cohesin onto DNA depends on the evolutionary conserved C terminus of Scc2, which contains several HEAT repeats (Takahashi et al. 2008). The poorly conserved $\mathrm{N}$ terminus of Scc2 is required for binding to Scc4, and a complex of Scc4 and Scc2's $\mathrm{N}$ terminus is sufficient for binding to chromatin (Seitan et al. 2006; Takahashi et al. 2008). In vertebrate cells, Scc2 and Scc4 dissociate from chromosomes during mitosis, indicating that cohesin loading onto DNA is inhibited during this period (Gillespie and Hirano 2004; Watrin et al. 2006). In contrast, recent experiments in budding yeast suggest that cohesin can be loaded onto centromeric DNA during mitosis, when transiently separated sister chromatids reassociate during centromere "breathing." Surprisingly, this process seems to be independent of Scc2/Scc4 (Ocampo-Hafalla et al. 2007). It will therefore be interesting to test whether multiple pathways exist that can facilitate binding of cohesin to DNA.

In Xenopus egg extracts, cohesin loading onto DNA also depends on the assembly of prereplicative complexes (pre-RCs) on DNA (Gillespie and Hirano 2004; Takahashi et al. 2004), to which Scc2/Scc4 are recruited via binding to the protein kinase Cdc7 and either one of its activating subunits Dbf4 or Dfr4 (Takahashi et al. 2008). The fission yeast ortholog of Cdc7, Hsk1, is also required for cohesin binding to pericentric heterochromatin (Takeda et al. 2001; Bailis et al. 2003), indicating that some aspects of Cdc7 function in cohesin loading may have been conserved during evolution. In budding yeast, however, the pre-RC protein Cdc6 is dispensable for cohesin loading (Uhlmann and Nasmyth 1998), suggesting that recruitment of Scc2/Scc4 to DNA may occur by different mechanisms in different species. Whether cohesin loading onto DNA depends on pre-RCs in other organisms remains unknown, but the observation that cohesin binds to DNA during telophase in mammalian cells-i.e., at a time when pre-RCs are known to assemble (Mendez and Stillman 2000)-is consistent with this possibility. However, it is possible that pre-RCs are only required for the initial loading of Scc2/Scc4 onto DNA but not for keeping it there, because Scc2 and Scc4 persist on chromatin throughout interphase, although pre-RCs only exist until S phase.

\section{Establishment of sister chromatid cohesion in $\mathrm{S}$ phase}

Cohesion can only be established once DNA has been replicated during $S$ phase. Interestingly, however, genetic experiments in budding yeast have shown that cohesion can normally also not be established once DNA replication has been completed, although cohesin can still be loaded onto DNA during G2 phase (for exceptions, see below) (Uhlmann and Nasmyth 1998; Haering et al. 2004).

The establishment of sister chromatid cohesion depends on an acetyltransferase, called Ecol/Ctf7 (Skibbens et al. 1999; Toth et al. 1999; Ivanov et al. 2002; Unal et al. 2007). This enzyme is not needed for loading of cohesin onto DNA, and interestingly, Ecol also becomes dispensable once cohesion has been formed, indicating that Eco1 has a specific role during establishment of cohesion. Recent work has shown that a key function of Ecol is to acetylate cohesin on two lysine residues that are both located on the ATPase "head" domain of Smc3 (Ben-Shahar et al. 2008; Unal et al. 2008). Mutation of these lysine residues to nonacetylatable amino acid residues causes cohesion defects and lethality in yeast, whereas yeast cells can even live in the absence of the otherwise essential Ecol enzyme if they express another mutant of Smc3 that might mimic the acetylated state (Ben-Shahar et al. 2008; Unal et al. 2008). Similar observations have been made in human cells that contain two Eco1-related enzymes called Esco1/Efo1 and Esco2/Efo2. Cohesion defects have been observed after depletion of either one of these proteins (Hou and Zou 2005), but only depletion of Escol was found to cause acetylation defects on Smc3 (Zhang et al. 2008), indicating that Escol and Esco2 perform at least partially nonoverlapping functions. Importantly, a mild cohesion defect that is seen after Escol depletion can be rescued by expression of an acetyl-mimetic mutant of Smc3 (Zhang et al. 2008), indicating that Smc3 is an important target of Escol in human cells. It remains to be clarified whether Smc3 is Escol's only relevant substrate, and who the targets of Esco2 are.

Further important insight into the function of Ecol in cohesion establishment comes from genetic interaction studies. These have revealed that the $S$. pombe ortholog of Eco1, Eso1, becomes dispensable for viability if the pds5 gene is deleted (Tanaka et al. 2001). This observation implies that Esol has to inactivate some property of Pds5 that would otherwise inhibit cohesion establishment (note, however, that inhibition of cohesion establishment cannot be the only role of Pds5, because the protein is also essential for cohesion maintenance during a prolonged G2-phase arrest) (Tanaka et al. 2001). In budding yeast, the lethality of Eco1 deletion is furthermore suppressed by inactivation of Rad61/Wpl1 (Ben-Shahar et al. 2008), which in other organisms is required for efficient dissociation of cohesin from DNA (Gandhi et al. 2006; Kueng et al. 2006; Bernard et al. 2008). Similarly, it has been observed in human cells that cohesion defects caused by Esco2 depletion can be rescued by codepletion of Wapl (Gandhi et al. 2006). An important implication of these findings is that sister chromatid cohesion can principally be established in the absence of Ecol. The main function of Ecol and its orthologs may thus be to protect cohesin from precocious dissociation from DNA. How Ecol achieves this task is not known, but it is conceivable that Smc3 acetylation renders co- 
hesin resistant to Wapl and its binding partner Pds5, or that acetylation stabilizes protein-protein interactions of cohesin core subunits. The latter possibility is supported by the observation that in budding yeast Ecol strengthens sister chromatid cohesion, even in the absence of Rad61/Wpl1 (Ben-Shahar et al. 2008).

Understanding the function of Ecol may also reveal how cohesion establishment is normally linked to DNA replication, because Ecol has been found to interact physically with several proteins that are required for DNA replication, such as replication factor C (RFC) complexes (Kenna and Skibbens 2003) and PCNA (Moldovan et al. 2006). Based on ChIP experiments, it has further been suggested that in budding yeast Ecol travels along DNA together with replication forks (Lengronne et al. 2006). This observation and the finding that cohesin is preferentially acetylated when it is bound to chromatin (Unal et al. 2008) suggest that cohesion establishment in S phase occurs at replication forks. This notion is also supported by the observation that mild cohesion defects are caused by depletion or mutation of several nonessential components of the replisome, such as Ctf4, the RFC components Rfc4 and Ctf18, the DNA helicase Chl1, the checkpoint proteins Tof1 and Csm3, and the DNA polymerases $\varepsilon$ and $\kappa$ (Wang et al. 2000; Mayer et al. 2001, 2004; Edwards et al. 2003; Petronczki et al. 2004; Skibbens 2004; Suter et al. 2004; Parish et al. 2006; Farina et al. 2008). Direct interactions between Smc1 and replication proteins have also been reported, but only if a tagged version of Smcl is transiently overexpressed in mammalian cultured cells (Ryu et al. 2006).

The ring model of cohesion can explain many properties of cohesin-DNA interactions, but it remains a mystery how both sister chromatids can become trapped during replication within a single cohesin ring. Cohesin binds to DNA already before DNA replication, and it has thus been speculated that DNA replication may occur directly through the cohesin ring (Haering et al. 2002; Gruber et al. 2003). This idea could explain how sister chromatids become connected by cohesion, whereas nonsister sequences do not, but it is unclear whether the replication fork with its numerous associated proteins could indeed pass through a proteinaceous ring of 35-40 $\mathrm{nm}$ inner diameter. It has recently been reported that cohesin complexes that have been loaded onto DNA before replication are sufficient to establish cohesion (Lengronne et al. 2006). Although this observation is consistent with the "replication-through-the-ring" model, it remains equally well possible that cohesin rings have to be opened transiently during passage of the replication fork. Such a scenario could perhaps explain why budding yeast cells lacking Rad61/Wpl1 have a mild cohesion defect (Warren et al. 2004). Rad61/Wpll might facilitate the transient opening of DNA-bound cohesin complexes when replication forks move through cohesin-binding sites, and defects in this process could decrease the efficiency of cohesion establishment.

An important observation that may shed further light on the mechanism of cohesion establishment comes from fluorescence recovery after photobleaching (FRAP) experiments in mammalian cells (Fig. 3). These studies have revealed that cohesin binds to DNA dynamically during G1 phase, but that approximately half of all chromatin-bound cohesin complexes bind to DNA very stably in G2 (Gerlich et al. 2006). The ability of cohesin to bind to DNA stably depends on DNA replication, consistent with the possibility that stably bound cohesin complexes are the ones that have established sister chromatid cohesion. Evidence for stable binding of cohesin to chromosomes in G2 phase has also been obtained in $S$. pombe, but surprisingly this stabilization occurs during $S$ phase in a manner that is independent of Esol and of DNA replication (Bernard et al. 2008). It therefore remains to be seen whether stable binding of cohesin to DNA precedes the establishment of sister chromatid cohesion, or is rather a consequence of cohesion. As discussed above, there is evidence that the hinge regions of Smc1 and Smc3 have a role in loading of cohesin onto DNA (Gruber et al. 2006). However, in S. cerevisiae, Smcl hinge mutations also have been identified that do not fully prevent binding of cohesin to chromatin, but which are unable to establish cohesion (Milutinovich et al. 2007). It will be interesting to test whether these mutated complexes might be specifically defective in generating the stable DNA-binding mode that is associated with cohesion establishment.

In vertebrates, sororin might also have an important function in establishing sister chromatid cohesion, because FISH experiments have shown that depletion of this protein from cultured human cells causes severe cohesion defects already in G2 phase, without reducing the amount of cohesin that is bound to chromatin (Schmitz et al. 2007). Interestingly, sororin depletion decreases the subpopulation of cohesin that is stably bound to DNA, suggesting that sororin somehow enables cohesin to establish cohesive structures. It also remains possible that sororin is only required in G2 phase for maintenance of sister chromatid cohesion. One study has further proposed that sororin functions specifically in mitosis to protect cohesin from precocious dissociation from DNA (Diaz-Martinez et al. 2007b). However, it is difficult to reconcile this hypothesis with the observation that sororin-depleted cells show cohesion defects already in G2 phase (Schmitz et al. 2007).

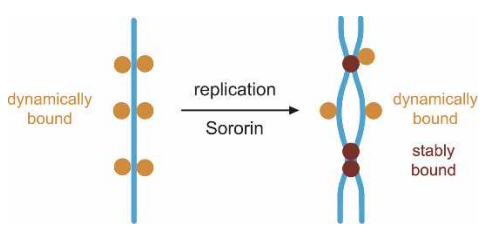

Figure 3. Dynamics of the cohesin-chromatin interaction in mammalian cells. Cohesin associates dynamically with chromatin throughout interphase. During replication, about half of the chromatin-associated cohesin molecules become stably bound to chromatin (Gerlich et al. 2006). Sororin is also needed for stable binding of cohesin to chromatin (Schmitz et al. 2007). It has been proposed that stably chromatin-bound cohesin molecules represent complexes that have established cohesion (Gerlich et al. 2006). See the text for details. 
Although sister chromatid cohesion is normally only established in S phase, three exceptions to this rule have been described recently in budding yeast. The best studied of these situations is observed when DNA DSBs are created during G2 phase. These breaks activate DNA damage response pathways that allow de novo formation of cohesion once DNA replication has been completed (Strom et al. 2007; Unal et al. 2007; see below). As in S phase, this process depends on Ecol. Ecol is also needed for the transient reassociation of sister chromatids during centromere "breathing," which raises the interesting possibility that cohesion might also be locally re-established at centromeres during metaphase (OcampoHafalla et al. 2007). Finally, a partial defect in sister chromatid cohesion that is observed after depletion of the origin recognition complex (ORC) subunit Orc2 can be restored when Orc2 is expressed in G2 phase (Shimada and Gasser 2007). Surprisingly, genetic experiments suggest that ORC mediates sister chromatid cohesion through a mechanism that is distinct from cohesion establishment by cohesin and Ecol. The molecular basis of this mechanism, and if it also exists in other eukaryotes, is presently unknown.

\section{The prophase pathway of cohesin dissociation}

When vertebrate cells enter mitosis, the prophase pathway removes the bulk of cohesin from chromosome arms, whereas cohesin remains bound to centromeres (Fig. 4; Waizenegger et al. 2000). Also Scc2/Scc4, CTCF, and the cohesin-associated proteins Wapl, Pds5A, and sororin are removed from chromosomes in prophase (Sumara et al. 2000; Rankin et al. 2005; Gandhi et al. 2006; Kueng et al. 2006; Watrin et al. 2006; Wendt et al.

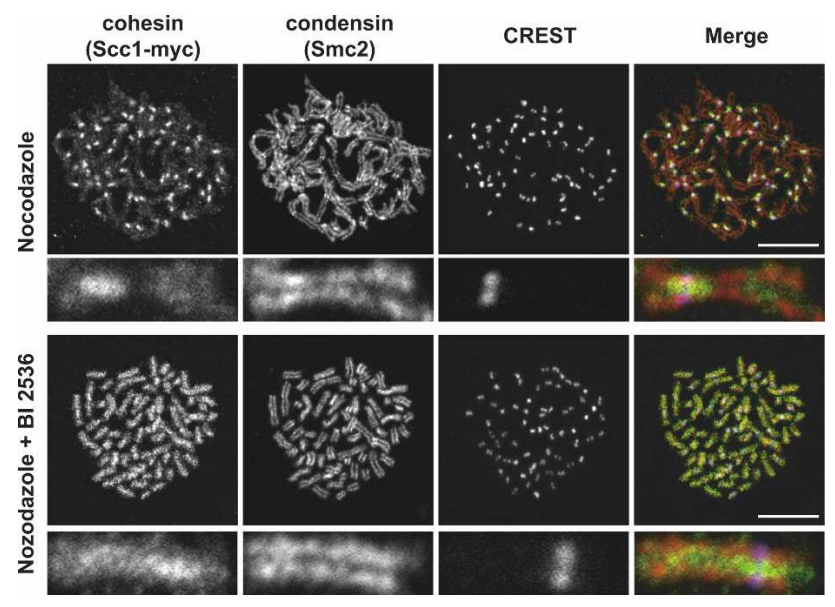

Figure 4. Regulation of cohesin removal from chromosome arms. Chromosome spreads obtained from cells arrested in prometaphase by nocodazole were stained for cohesin (Scc1-myc) as well as for condensin and CREST as a markers of chromosome axes and kinetochores, respectively. Cohesin is removed from chromosome arms in control cells, but remains on chromosome arms in cells treated with the Plk1 inhibitor BI2536. A similar phenotype is observed after inactivation of Aurora B kinase, condensin I, and Wapl. Bar, $10 \mu \mathrm{m}$. Reprinted from Lenart et al. (2007), with permission from Elsevier (C 2007).
2008), in contrast to the situation in yeast where the bulk of cohesin remains bound to chromosomes until metaphase and where Scc2/Scc4 is chromatin bound throughout the cell cycle (Ciosk et al. 2000). The vertebrate prophase pathway is independent of the APC/C (Sumara et al. 2000), which is needed for activation of separase later in metaphase, and correspondingly, no cleavage of Scc1 is observed when cohesin is removed from chromosomes during prophase (Waizenegger et al. 2000). Instead, cohesin dissociation depends on Polo-like kinase 1 (Plk1) (Losada et al. 2002; Sumara et al. 2002; Gimenez-Abian et al. 2004; Lenart et al. 2007), an enzyme that is activated early in mitosis and is translocated from the cytoplasm into the nucleus toward the end of prophase. In mitosis, the Scc1 and SA1/SA2 subunits of cohesin become phosphorylated, and in mitotic Xenopus egg extracts Plk1 is required for these modifications (Sumara et al. 2002). These phosphorylation reactions decrease binding of cohesin to chromatin, suggesting that cohesin-DNA interactions might directly be controlled by phosphorylation (Sumara et al. 2002). This notion is also supported by the observation that expression of a nonphosphorylatable mutant of SA2 reduces dissociation of cohesin from chromosomes in prophase and prometaphase, whereas expression of nonphosphorylatable Sccl does not cause such an effect (Hauf et al. 2005). These observations indicate that Plk1 contributes to cohesin dissociation by phosphorylating SA2.

Another mitotic kinase, Aurora B, is also required for efficient dissociation of cohesin from chromosomes in prophase, even though this kinase does not phosphorylate cohesin subunits in vitro (Losada et al. 2002; Gimenez-Abian et al. 2004). It is therefore possible that Aurora $\mathrm{B}$ is indirectly required for cohesin dissociation by regulating other proteins. One candidate for such a protein is condensin I, whose binding to chromosomes depends on Aurora B (Lipp et al. 2007) and that is also required for efficient dissociation of cohesin from chromosomes (Hirota et al. 2004). However, it is not clear whether condensin I is Aurora B's only relevant target in the prophase pathway of cohesin dissociation, because condensin I only binds to chromosomes after breakdown of the nuclear envelope in prometaphase; i.e., after cohesin dissociation has already been initiated (Hirota et al. 2004). Another cohesin regulator whose chromosomal location is controlled by Aurora B is Sgol (see below), but also in this case, it is not known whether Aurora B's role in cohesin dissociation can exclusively be explained by the influence of Aurora B on this protein (McGuinness et al. 2005; Dai et al. 2006; Lipp et al. 2007).

Although SA2 phosphorylation is required for efficient cohesin dissociation, studies of the Wapl protein indicate that cohesin phosphorylation is not sufficient to remove cohesin from chromosomes. If Wapl is depleted from mammalian cells, cohesin dissociation in prophase is reduced, but in this case, much more dramatically than after inactivation of Plk1, Aurora B or condensin I (Gandhi et al. 2006; Kueng et al. 2006). For example, if Plk1 is inhibited, more cohesin persists on chromosome arms than normally, but these amounts are still so small 
that they can only be detected reliably in cells that express epitope-tagged cohesin subunits (Lenart et al. 2007). In contrast, after depletion of Wapl, endogenous cohesin can easily be detected on chromosomes in prophase, prometaphase, and even metaphase, a situation that is normally only observed for cells in interphase where much cohesin is bound to chromatin (Gandhi et al. 2006; Kueng et al. 2006). Conversely, when Wapl is overexpressed, sister chromatid cohesion is lost precociously. These observations indicate that Wapl has a key role in the prophase pathway of cohesin dissociation.

Interestingly, Wapl depletion does not abolish phosphorylation of SA2 on chromosomes, indicating that the role of Wapl in the prophase pathway is not simply to enable cohesin phosphorylation by Plk1 (Kueng et al. 2006). This notion is further supported by the observation that Wapl also controls the dynamics of cohesinchromatin interactions in interphase, where Plk1 is inactive. If Wapl is depleted, more cohesin binds to chromatin also in interphase, and FRAP experiments have shown that the residence time of cohesin complexes on chromatin is increased (Kueng et al. 2006). These observations indicate that Wapl is required for dissociation of cohesin from chromatin both in mitosis and interphase. How Wapl contributes to removal of cohesin from chromatin is unknown, but it is interesting to note that Wapl interacts with SA2 (Gandhi et al. 2006; Kueng et al. 2006), whose phosphorylation is also required for cohesin dissociation in mitosis. It is therefore possible that SA2 phosphorylation changes cohesin in a way that facilitates cohesin dissociation by Wapl. Like separase, Wapl might then be able to open the cohesin ring, although in this case, through a mechanism that does not depend on cleavage of Sccl. Because Wapl interacts with SA2 and Scc1, which bind to the ATPase heads of Smc1 and Smc3, and because these ATPases are needed for loading of cohesin onto DNA, it will also be interesting to test whether Wapl mediates cohesin dissociation by controlling the ATPase activity of Smc1 and Smc3.

\section{Functions of the prophase pathway}

During prophase and prometaphase, sister chromatids become partially separated from each other in their arm regions, but not at centromeres. As a result, chromosomes in prometaphase and metaphase appear " $\mathrm{X}$ "shaped, or " $\mathrm{V}$ "-shaped in the case of species such as the mouse where centromeres are located next to telomeres (Fig. 5). This "resolution" of sister chromatids in chromosome arm regions is prevented if the prophase pathway is inhibited by inactivation of Plk1, Aurora B, condensin I, or Wapl, or by expression of nonphosphorylatable SA2 (Fig. 5; Losada et al. 2002; Gimenez-Abian et al. 2004; Hirota et al. 2004; Hauf et al. 2005; Gandhi et al. 2006; Kueng et al. 2006). In these experiments, the strength of the resolution defect correlates well with the amount of cohesin that persists on chromosome arms, and the resolution defect that is caused by Wapl depletion can be partially rescued by codepletion of cohesin (Gandhi et al. 2006). The " $\mathrm{X}$ " and "V" shapes of mitotic

\begin{tabular}{|c|c|c|c|}
\hline \multicolumn{2}{|c|}{$\begin{array}{l}\text { Prometaphase } \\
\text { chromosomes } \\
\text { Control Aberrant }\end{array}$} & Phenotype & Observed after inactivation of: \\
\hline 17 & & $\begin{array}{l}\text { Precocious } \\
\text { sister chromatid } \\
\text { separation }\end{array}$ & $\begin{array}{c}\text { Cohesin, Pds5A, Pds5B, Scc2, Scc4 } \\
\text { Sororin, Esco1, Esco2, Sgo1, San, } \\
\text { Haspin, PHB2, and others }\end{array}$ \\
\hline (2) & & $\begin{array}{c}\text { Unresolved } \\
\text { sister chromatids }\end{array}$ & Wapl, Plk1, Aurora B, Condensin I \\
\hline & & $\begin{array}{l}\text { Diplochromosomes: } \\
\text { re-replicated } \\
\text { non-disjoined } \\
\text { chromatids }\end{array}$ & $\begin{array}{c}\text { Separase } \\
\text { (at low frequency also after } \\
\text { expression of non-cleavable Scc1) }\end{array}$ \\
\hline
\end{tabular}

Figure 5. Cohesion phenotypes in mammalian cells. Giemsastained chromosomes from human (X-shaped) and mouse (Vshaped) are shown. Precocious sister chromatid separation is observed after inactivation of a variety of cohesion regulators that are required at different stages of the cohesion cycle. Unresolved sister chromatids are observed when proteins that regulate the removal of cohesin during prophase are inactivated. Diplochromosomes result from rereplication of sister chromatids that were not separated during the previous mitosis. This phenotype is observed after inactivation of separase as well as at low frequency after expression of noncleavable Scc1.

chromosomes are thus a result of the differential removal of cohesin from chromosome arms versus centromeres (Waizenegger et al. 2000).

What the physiological functions of the prophase pathway and of sister chromatid resolution are has been a long-standing question that has still not been fully answered yet. It has been speculated that cohesin dissociation from chromosome arms may be a prerequisite for chromosome condensation, which occurs around the same time, but so far no major condensation defects have been observed in cells in which the prophase pathway has been compromised. It is also conceivable that sister chromatid resolution increases the fidelity of chromosome segregation. For example, it is possible that the partial separation of chromosome arms provides directionality to reactions catalyzed by topoisomerases. These enzymes can catalyze catenation reactions as well as decatenation reactions, and spatial resolution between sister chromatid arms may therefore help to shift the reaction equilibrium in favor of decatenation reactions.

Finally, it has been proposed that the prophase pathway may have an indirect but important role in the ability of cohesin to regulate gene expression (Wendt et al. 2008). This hypothesis is based on the observation that the prophase pathway removes cohesin from chromosomes without Sccl cleavage (Waizenegger et al. 2000) and that separase, once activated in metaphase, preferentially cleaves cohesin that is bound to chromatin (Waizenegger et al. 2000; Hornig and Uhlmann 2004). These results indicate that the prophase pathway spares cohesin from destruction by separase. As a result, vertebrate cells exit mitosis with almost unchanged amounts of intact cohesin complexes, which can be loaded onto chromatin immediately after reformation of the nuclear envelope. This ability may be of great physiological significance, because recent evidence suggests that cohesin has important effects on gene regulation already in G1 
phase; i.e., before cohesion has been established (Wendt et al. 2008).

\section{Protection of centromeric cohesin from the prophase pathway}

Sister chromatid cohesion normally persists at centromeres until all chromosomes have been bioriented on the mitotic spindle. Until this metaphase state has been reached, the initiation of anaphase is inhibited by a surveillance mechanism, known as the spindle checkpoint, which inhibits the APC/C and thereby prevents activation of separase (for review, see Peters 2006). However, if the Sgol protein is inactivated, centromere cohesion can be lost already during prometaphase; i.e., before spindle assembly has been completed (Salic et al. 2004; Tang et al. 2004; Kitajima et al. 2005; McGuinness et al. 2005). Loss of Sgol function does not inactivate the spindle checkpoint, which would lead to precocious activation of APC/C and separase. Instead, cohesin dissociates prematurely from centromeres if Sgol is inactivated, which leads to loss of sister chromatid cohesion in the absence of separase activity. Sgol is therefore believed to be a protein that protects cohesin from the prophase pathway and thereby maintains cohesion until separase becomes active in metaphase.

Interestingly, in budding and fission yeasts, and in human cells, Sgol interacts with a protein phosphatase $2 \mathrm{~A}$ (PP2A) complex, which like Sgol itself is enriched at centromeres and is required for maintaining cohesion in early mitosis in human cells and in meiosis I in yeast (Kitajima et al. 2006; Riedel et al. 2006; Tang et al. 2006). In vitro, the Sgol-PP2A complex is able to dephosphorylate the SA2 subunit of cohesin (Kitajima et al. 2006), and in cultured mammalian cells the cohesion defect that is caused by Sgol depletion can be restored by expression of nonphosphorylatable SA2 (McGuinness et al. 2005). Sgol may therefore protect cohesin from the prophase pathway by recruiting PP2A to centromeres, where PP2A may revert phosphorylation of cohesin, which would otherwise lead to its dissociation from chromosomes.

The recruitment of Sgol to centromeres depends on the protein kinase Bub1 and also on HP1 $\alpha$ (Tang et al. 2004; Kitajima et al. 2005; Yamagishi et al. 2008). Like Sgol depletion, loss of Bubl causes separation of sister chromatids. However, Bub1 depletion also leads to inactivation of the spindle checkpoint, and thus to precocious separase activation, and cohesion defects that are seen in Bubl mutants may thus also be due to checkpoint inactivation and not only to defects in Sgol localization (Perera et al. 2007). Inhibition of Aurora B kinase also affects Sgol localization by causing redistribution of Sgo1 to chromosome arms (Dai et al. 2006; Kueng et al. 2006; Resnick et al. 2006; Lipp et al. 2007). This phenomenon might, in part, explain the observed requirement for Aurora B in the prophase pathway.

The observation that Sgo1, PP2A, and cohesin are normally enriched at centromeres in mammalian cells, and that cohesion is particularly tight in this chromosomal region, indicates that cohesin is best protected from the prophase pathway by Sgol at the centromere. However, during an unperturbed mitosis, cohesion between chromosome arms is also never dissolved completely. Only if cells remain in prometaphase for prolonged periods of times can arm cohesion be abrogated completely, resulting in chromosomes with "open" arms. This situation is typically seen when cells are treated with microtubule poisons, which keep the spindle checkpoint active and thus arrest cells in prometaphase (Rieder and Palazzo 1992). It was initially believed that complete opening of chromosome arms under these conditions was due to continuous activity of the prophase pathway (GimenezAbian et al. 2004), but it has recently been shown that cleavage of Scc1 by small amounts of separase activity are also necessary for this phenomenon (Diaz-Martinez et al. 2007a; Nakajima et al. 2007). The requirement for separase in chromosome arm opening is abrogated if Sgo1 is depleted, suggesting that small amounts of Sgo1 may also protect some cohesin on chromosome arms during the early stages of mitosis (Nakajima et al. 2007).

Beside Sgol, a number of other proteins have also been reported to be required for sister chromatid cohesion in early mitosis (Table 2). Some of these may have a direct role in cohesin protection. For example, haspin is a histone H3-Thr 3 kinase that is required for persistence of cohesin at mitotic centromeres, although haspin is dispensable for Sgol recruitment to these sites. Conversely, haspin overexpression prevents dissociation of cohesin from chromosome arms (Dai et al. 2006). Haspin may therefore negatively regulate the prophase pathway at centromeres. Another potential cohesin protector is PHB2, whose depletion causes cohesion defects in mitosis, but not yet in G2 phase (Takata et al. 2007). For some of the other cohesin regulators it is less clear whether these proteins are specifically needed in mitosis, or whether mitotic defects that are caused by their depletion are the consequence of earlier cohesion defects. In some studies it has been argued that a given protein functions specifically in mitotic cohesin protection because cohesion defects could be reverted by inactivation of Plk1, which is needed for the prophase pathway. However, cohesion defects caused by depletion of cohesin core subunits can in some cases also be "rescued" by Plk1 inactivation (J. Schmitz and J.-M. Peters, unpubl.). It is therefore possible that partial cohesion defects that remain hypomorphic in interphase are only uncovered in mitosis where the prophase pathway removes most cohesin from chromosomes. To determine when a cohesion defect first occurs, it is therefore important to assess sister chromatid cohesion also in G2 phase by FISH experiments. Likewise, it is important to exclude that a putative cohesin regulator does not compromise the spindle checkpoint, because checkpoint defects would also indirectly lead to precocious loss of cohesion.

\section{Cohesin cleavage by separase}

Once cells have bioriented all of their chromosomes on the mitotic or meiotic spindle, the spindle checkpoint is 
Table 2. Proteins implicated in sister chromatid cohesion in mitosis or meiosis

\begin{tabular}{|c|c|c|c|}
\hline Regulator & Species & Proposed function in cohesion & References \\
\hline PP2A & S.c., S.p., H.s. & $\begin{array}{l}\text { Protection of centromeric cohesion, possibly via SA2 } \\
\text { dephosphorylation; interacts with Sgo1 and Sgo2 }\end{array}$ & See the text \\
\hline Sgol & S.c., S.p., Z.m., D.m., H.s. & Protection of centromeric cohesion; interacts with PP2A & See the text \\
\hline Sgo2 & S.c., S.p., M.m., H.s. & Protection of centromeric cohesion; interacts with PP2A & $\begin{array}{l}\text { Kitajima et al. 2004; Lee et al. } \\
2008\end{array}$ \\
\hline Bub1 & S.p., H.s., M.m. & $\begin{array}{l}\text { Recruitment of Sgol to centromeres; essential for spindle } \\
\text { checkpoint }\end{array}$ & See the text \\
\hline Haspin & H.s. & $\begin{array}{l}\text { Centromeric cohesion, possibly via phosphorylation of } \\
\text { histone H3T3. }\end{array}$ & See the text \\
\hline Astrin & H.s. & Centromeric cohesion, possibly via regulation of separase & Thein et al. 2007 \\
\hline Dicer & S.p., G.g., H.s. & $\begin{array}{l}\text { Centromeric cohesion, possibly via regulation of } \\
\text { heterochromatin structure }\end{array}$ & $\begin{array}{l}\text { Hall et al. 2003; Fukagawa et } \\
\text { al. } 2004\end{array}$ \\
\hline San & D.m., H.s. & $\begin{array}{l}\text { Centromeric cohesion, possibly via acetyltransferase } \\
\text { activity }\end{array}$ & $\begin{array}{l}\text { Williams et al. 2003; Hou et al. } \\
2007\end{array}$ \\
\hline ORD & D.m. & Centromeric acccumulation of cohesin in meiosis I & See the text \\
\hline Moal & S.p. & $\begin{array}{l}\text { Centromeric cohesion in meiosis I, possibly via } \\
\text { interaction with Rec } 8\end{array}$ & $\begin{array}{l}\text { Yokobayashi and Watanabe } \\
2005\end{array}$ \\
\hline PHB2 & H.s. & Centromeric cohesion & See the text \\
\hline ATRX & H.s. & Centromeric cohesion & Ritchie et al. 2008 \\
\hline Cenp-F & H.s. & Centromeric cohesion & Holt et al. 2005 \\
\hline $\mathrm{Cdk} 11^{\mathrm{p} 58}$ & H.s. & Centromeric cohesion & Hu et al. 2007 \\
\hline RecQL4 & M.m. & Centromeric cohesion & Mann et al. 2005 \\
\hline
\end{tabular}

(S.c.) Saccharomyces cerevisiae; (S.p.) Schizosaccharomyces pombe; (Z.m.) Zea mays; (D.m.) Drosophila melanogaster; (G.g.) Gallus gallus; (M.m.) Mus musculus; (H.s.) Homo sapiens.

inactivated and the APC/C becomes active. This leads to ubiquitylation and subsequent degradation of numerous APC/C substrates, including the separase inhibitor securin and cyclin B, the activating subunit of Cdk1. These reactions enable activation of separase (for review, see Peters 2002). Before APC/C is active, separase is inhibited in interphase and early mitosis by physical association with securin, which prevents separase from recognizing its substrates (Hornig et al. 2002; Waizenegger et al. 2002). Whereas separase activity is controlled by securin orthologs in all species analyzed so far, separase in vertebrates is in addition inhibited by Cdk1-mediated phosphorylation and by physical binding to Cdk1's cyclin B subunit (Stemmann et al. 2001; Gorr et al. 2005; X. Huang et al. 2005; Huang et al. 2008). In vertebrate cells, APC/C activation therefore relieves separase from two inhibitory mechanisms via ubiquitylation of securin and cyclin B. Vertebrate separase is also subject to another level of regulation, namely, proteolytic autocleavage (Waizenegger et al. 2000), but this reaction is not essential for cohesin cleavage in vitro (Waizenegger et al. 2002; Zou et al. 2002) and its in vivo function remains poorly understood (Papi et al. 2005).

Once separase is active, it cleaves Sccl at two sites, which leads to destruction of the cohesin ring, dissociation of cohesin from chromosomes, and separation of sister chromatids. The Scc1 cleavage reaction was first discovered in budding yeast, where most Sccl is destroyed in mitosis, and where Sccl cleavage is both required and sufficient for sister chromatid separation (Uhlmann et al. 1999, 2000). The cleavage is enhanced, although not strictly dependent on phosphorylation of Scc1 by the budding yeast ortholog of Plk1, Cdc5 (Alex- andru et al. 2001), and the resulting proteolytic fragments of Scc1 are degraded by the ubiquitin-dependent $\mathrm{N}$-end rule pathway (Rao et al. 2001). In the next cell cycle, Sccl only reaccumulates at the end of G1 phase (Michaelis et al. 1997), presumably because APC/C is inactivated at this time, which enables accumulation of securin and inhibition of separase.

In contrast to the situation in budding yeast, only very little Scc1 cleavage can be detected when fission yeast and vertebrate cells enter metaphase (Tomonaga et al. 2000; Waizenegger et al. 2000). In vertebrates, several observations indicate that this situation is caused by specific cleavage of the few cohesin complexes that remain bound to chromosomes at this time in metaphase, whereas the bulk of cohesin that has been removed from chromosomes in prophase appears to be spared from destruction. This notion is supported by the observation that $\mathrm{Sccl}$ cleavage occurs at the time when cohesin disappears from centromeres-i.e., at the metaphase-anaphase transition-and by the finding that cleavage of Scc1 in a cell free Xenopus egg extract system is much stimulated by the addition of chromatin (Waizenegger et al. 2000).

Although separase only cleaves $\sim 10 \%$ of cohesin complexes in mitotic mammalian cells (Waizenegger et al. 2000; Gerlich et al. 2006), these reactions are essential for sister chromatid separation, because both expression of noncleavable mutants of Scc1 and deletion of separase genes cause defects in chromosome segregation (Hauf et al. 2001; Kumada et al. 2006; Wirth et al. 2006). Genetic experiments in fission yeast and Drosophila indicate that separase is likewise essential for anaphase in these species (Tomonaga et al. 2000; Jager et al. 2001). In con- 
trast to the situation in budding yeast, it is not yet known whether separase activation alone is sufficient for sister chromatid separation in animal cells, or whether the prophase pathway of cohesin dissociation is also required. The current evidence suggests that the prophase pathway is not essential for anaphase because sister chromatid separation is delayed, but not prevented, when this pathway is compromised, for example, by depletion of Wapl. In these cells, more cohesin complexes remain bound to chromosomes until metaphase than normally, but these complexes disappear precisely at the time when sister chromatids begin to separate (Kueng et al. 2006). It is therefore possible that separase can compensate a reduction in the prophase pathway by cleaving more cohesin than normally.

It also has been suggested that activation of both the prophase and separase pathways is still not sufficient to dissolve all cohesion between sister chromatids. It was reported that depletion of the poly-ADP ribose polymerase tankyrase from mammalian cultured cells arrests cells in mitosis at a stage where APC/C and separase are active, cohesin has been removed from centromeres and chromosome arms, but telomeres remain cohesed due to the persistence of cohesin ${ }^{\mathrm{SA} 1}$ at these sites (Dynek and Smith 2004; Canudas et al. 2007). However, a separate study showed that tankyrase depletion leads to defects in spindle assembly and a spindle checkpoint-dependent arrest in prometaphase where $\mathrm{APC} / \mathrm{C}$ is inhibited and where, presumably, the bulk of separase also remains inactive (P. Chang et al. 2005). It is therefore more plausible to think that tankyrase depletion maintains cohesion indirectly by activating the spindle checkpoint.

Like Scc1, Rec8 is cleaved by separase, and experiments in yeast, C. elegans, and mice indicate that these reactions are also essential for chromosome segregation in meiosis (Buonomo et al. 2000; Siomos et al. 2001; Kitajima et al. 2003b; Terret et al. 2003; Kudo et al. 2006). The regulation of Rec8 in meiosis is also similar to the regulation of Scc1 in mitosis, as the protection of both proteins at centromeres depends on Sgol and PP2A. This is remarkable because Sgol and PP2A protect Scc1 from the prophase pathway (see above), whereas the same proteins protect Rec 8 from cleavage by separase (Katis et al. 2004; Kitajima et al. 2004, 2006; Marston et al. 2004; Rabitsch et al. 2004; Hamant et al. 2005; Riedel et al. 2006; Lee et al. 2008). It is possible that both protection mechanisms rely on dephosphorylation of cohesin by PP2A, because there is evidence that SA2 dephosphorylation prevents cohesin dissociation in mitosis (see above), and that Rec8 dephosphorylation reduces cohesin cleavage by separase (Brar et al. 2006).

\section{Functions of cohesin in DNA damage control}

The $S$. pombe ortholog of Scc1, called $\operatorname{Rad} 21$, and the $S$. cerevisiae ortholog of Wapl, Rad61/Wpl1, were first identified in genetic screens for mutants that are hypersensitive to DNA damage (Birkenbihl and Subramani 1992; Game et al. 2003), indicating that cohesin has important functions in DNA damage response pathways.
Experiments in budding yeast indicated that cohesin mutants are defective in repairing damaged DNA, but not in checkpoint pathways that delay cell cycle progression in response to damaged DNA (Sjogren and Nasmyth 2001). These studies also provided evidence that DNA damage repair depends on the ability of cohesin to mediate sister chromatid cohesion. This situation is presumably due to the fact that DNA DSBs are preferentially repaired by recombination between sister chromatids, which might be facilitated by cohesion between them.

In recent years, it has been analyzed in detail how cohesin is regulated in response to DNA damage in budding yeast. These studies have not only provided insight into DNA damage pathways, but also have led to surprising discoveries about the regulation and mechanisms of cohesion establishment. Following DNA damage, cohesin accumulates in a large $50-100 \mathrm{~kb}$ domain that surrounds the DSB, independent of whether this break occurred in a cohesin-binding region (CAR) or not. This process depends on Scc2/Scc4, indicating that it depends on loading of cohesin to these sites (Strom et al. 2004; Unal et al. 2004). DNA damage further enables the de novo establishment of sister chromatid cohesion in G2 phase, both at the DSB sites and, remarkably, also genome-wide. As in S phase, cohesion establishment after DNA damage depends on Ecol, even though genetic experiments suggest that cohesion establishment in G2 phase is independent of any DNA replication (Strom et al. 2007; Unal et al. 2007). Recent work has further shown that cohesion establishment following DNA damage depends on the budding yeast ortholog of the ATR kinase, Mec1, and on the kinase Chk1, which might phosphorylate Scc1 on a particular serine residue (Heidinger-Pauli et al. 2008). Remarkably, expression of a mutant of Scc1 that mimics the phosphorylated state is sufficient to induce cohesion establishment in G2 phase, even in the absence of DNA damage. These observations suggest that Scc1 is the key target of the DNA damage response with respect to its ability to initiate cohesion establishment in post-replicative cells. Interestingly, it has further been observed that cohesion can also be established in G2 phase when Ecol is overexpressed (Unal et al. 2007). Also, in this case, cohesion establishment can occur in the absence of DNA damage. These results suggest that Sccl phosphorylation following DNA damage might change the susceptibility of cohesin to acetylation by Ecol, and/or that Ecol activity might be regulated during the cell cycle.

Cohesin may not only have to be loaded onto DNA in response to DNA damage, but might also have to be removed at some sites, because inactivation of separase or expression of noncleavable Sccl interferes with DNA repair in fission yeast in G2 phase (Nagao et al. 2004). It will also be interesting to test whether the increased DNA damage sensitivity of Rad61/Wpl1 mutants (Game et al. 2003) is related to the role of this protein in mobilizing cohesin that is already bound to DNA.

In vertebrate cells, cohesin is also recruited to DNA DSBs, and this process depends on the Smc5/Smc6 com- 
plex (Potts et al. 2006). Cohesin is thought to be required for DNA repair at these sites, but the regulation of cohesin in response to DNA damage has been less well studied in animal cells than in yeast (for review, see Watrin and Peters 2006). Depletion of sororin from cultured human cells also causes severe defects in the repair of DSBs, although normal amounts of cohesin are present on chromatin in these cells (Schmitz et al. 2007). This observation indicates that the ability of cohesin to establish cohesion is also important for DNA damage repair in higher eukaryotes.

As in budding yeast, cohesin subunits are phosphorylated in response to DNA damage, but in this case, phosphorylation occurs on Smc1 and Smc3, and is thought to be mediated directly by the kinases ATM (Ataxia Telangiectasia Mutated) and ATR (Kim et al. 2002; Yazdi et al. 2002; Garg et al. 2004; Hauf et al. 2005; Luo et al. 2008). Expression of a nonphosphorylatable mutant of Smc1 reduces DNA repair efficiency and cell survival in irradiated cultured mouse cells, a phenotype that is similar to the DNA damage sensitivity that is seen in cells lacking ATM (Kim et al. 2002; Yazdi et al. 2002; Kitagawa et al. 2004). Smcl may therefore be one of the key targets of ATM in the DNA damage response pathway. Interestingly, cells in which endogenous Smcl has been replaced by a nonphosphorylatable mutant are not only defective in repair of DNA damage, but also continue to synthesize DNA during S phase, whereas replication is inhibited by DNA damage in control cells (Kitagawa et al. 2004). Smcl phosphorylation might therefore not only have a role in DNA repair, but may also be needed for efficient activation of the S-phase checkpoint, in contrast to the situation in budding yeast where cohesin is not known to have a role in DNA damage checkpoints (Sjogren and Nasmyth 2001). However, it will be important to test whether Smc1 and Smc3 are actually phosphorylated as part of cohesin, or as subunits of the recombination complex RC-1, which also contains Smc1 and Smc3 (Jessberger et al. 1996; Stursberg et al. 1999). It also remains to be clarified how $\mathrm{Smcl} / \mathrm{Smc} 3$ phosphorylation contribute to DNA damage responses in molecular terms, and whether this role is restricted to S-phase checkpoints or not.

\section{Functions of cohesin in transcriptional control}

An early hint that cohesin's function may not be restricted to sister chromatid cohesion came from the observation that in vertebrate cells the binding of cohesin to chromatin does not correlate well at all with the time in the cell cycle during which sister chromatid cohesion exists, in contrast to the situation in budding yeast. As described above, in vertebrates, cohesin is loaded onto DNA already in telophase (i.e., long before cohesion is established), and the bulk of cohesin also dissociates from chromosomes again in prophase (i.e., before cohesion is dissolved) (Losada et al. 1998; Sumara et al. 2000; Gerlich et al. 2006). Had cohesin been first discovered in vertebrate cells, one might therefore not have concluded that a primary role of cohesin is to mediate sister chro- matid cohesion from $S$ phase until metaphase. Even more surprisingly for a cohesion protein, cohesin is expressed in a wide range of mammalian tissues (Sumara et al. 2000), including post-mitotic neurons that normally do not replicate their DNA again and can thus not establish cohesion (Wendt et al. 2008). The same has been observed for Pds5B in the mouse and for Rad21/Scc1 in Drosophila (Zhang et al. 2007; Pauli et al. 2008). These observations suggest that cohesin performs functions that are independent of its role in sister chromatid cohesion.

Genetic experiments in yeast and Drosophila suggested first that these functions may be related to chromatin structure and gene expression (for review, see Dorsett 2007). In S. cerevisiae, some Smc1 and Smc3 mutations inactivate the boundary elements that prevent spreading of silencing factors from the silent chromatin of the HMR locus into neighboring regions (Donze et al. 1999). Another effect on gene regulation was observed in Drosophila, where the fly ortholog of Scc2, Nipped-B, was discovered as a protein that facilitates activation of homeobox genes by distant transcriptional enhancers (Rollins et al. 1999). Surprisingly, mutation of cohesin has the opposite effect, which has led to the hypothesis that the ability of cohesin to dissociate from DNA and be reloaded is important for its role in regulating enhancer-promoter interactions (Rollins et al. 2004; Dorsett et al. 2005). Consistent with this possibility, mutation of Wapl in Drosophila also affects gene expression, because these mutations cause defects in position effect variegation (Verni et al. 2000).

Furthermore, indirect evidence for a role of cohesin in gene regulation comes from studies that have shown that mutations in cohesin and cohesin regulators can cause severe developmental defects in animals and humans. In C. elegans, Scc2's binding partner Scc4 was first identified as a protein, called MAU-2, which functions in axon guidance (Benard et al. 2004; Seitan et al. 2006; Watrin et al. 2006). Similarly, a screen for Drosophila mutants that are defective in axon pruning, the retraction of axons during nervous system development, identified mutations in Smcl and the Scc3 ortholog SA (Schuldiner et al. 2008). Also in vertebrates, cohesin mutations can cause developmental defects. In zebrafish, cohesin genes are required for expression of runx transcription factors and hematopoiesis (Horsfield et al. 2007), mice lacking the $P d s 5 B$ gene suffer from multiple developmental abnormalities (Zhang et al. 2007), and in humans, the developmental disorders Cornelia de Lange syndrome and Roberts/SC phocomelia syndrome can be caused by mutations in the genes of cohesin subunits and regulators (see below).

Remarkably, sister chromatid cohesion and cell proliferation are largely normal in cell lines derived from Cornelia de Lange patients, indicating that cohesin complexes in these cells must be able to establish and maintain cohesion, and that the mutations affecting these genes are hypomorphic. Nevertheless, it has initially been difficult to rule out the possibility that the transcriptional and developmental defects that are observed 
in cohesin mutants in various species are due to subtle defects in cohesion. However, several recent studies now provide clear evidence that at least some of cohesins' functions in gene regulation are independent of its role in cohesion. In human cells, depletion of cohesin causes changes in transcription at the imprinted H19/Igf2 locus (see below) not only during G2 phase, but also in cells synchronized in G1 phase, where cohesion does not exist (Wendt et al. 2008). In Drosophila Smcl mutants, the pruning defects that are observed in neurons can be reverted if Smcl is expressed post-mitotically in these cells (Schuldiner et al. 2008). This indicates that the function of cohesin in pruning must be post-mitotic, and thus independent of cohesion. Likewise, pruning defects are seen in Drosophila neurons if cohesin is only inactivated in post-mitotic cells by experimentally induced proteolysis of Rad21/Scc1 (Pauli et al. 2008).

How cohesin controls gene expression is a big mystery, although it is fair to assume that cohesin must mediate this effect by directly binding to DNA. An important hint to cohesin's gene regulatory role in mammalian cells comes from the observation that cohesin colocalizes with CTCF (Parelho et al. 2008; Stedman et al. 2008; Wendt et al. 2008). CTCF is known to function as a transcriptional insulator at some of its binding sites, such as the $\beta$ globin locus control region and the $H 19$ imprinting control region (ICR) (for review, see Wallace and Felsenfeld 2007). At the H19/Igf2 locus, the H19 ICR ensures that the $H 19$ gene is only transcribed from the maternal allele, whereas the neighboring Igf2 gene is only transcribed from the paternal allele (for review, see Bartolomei and Tilghman 1997). This imprinting mechanism depends on CTCF, which can bind to the H19 ICR on the maternal but not on the paternal allele because the latter is methylated on CpG sequences (Bell and Felsenfeld 2000; Hark et al. 2000). On the maternal allele, CTCF prevents Igf2 activation from distant enhancers, which under these conditions can activate $H 19$, whereas on the paternal allele, the same enhancers activate Igf2 but cannot stimulate $H 19$ transcription. Like CTCF, cohesin is also bound to the H19 ICR only on the maternal allele, presumably because CTCF is needed to properly position cohesin on DNA (see above). Remarkably, experiments in mammalian cultured cells indicate that cohesin is as important for proper transcriptional control at this imprinted locus as CTCF itself. If either CTCF or cohesin are depleted, Igf2 transcript levels increase and H19 transcripts decrease, consistent with the possibility that cohesin is needed for the insulator function of CTCF at the maternal H19 ICR (Wendt et al. 2008). In the future it will be important to verify these findings during mouse development in vivo, where imprinting normally occurs. It further remains to be seen how many of the 10,00015,000 CTCF/cohesin-binding sites in mammalian genomes function as insulators or as other transcriptional regulatory elements, and it will be interesting to address whether these sites function simultaneously, as sites where sister chromatid cohesion is established.

Finally, it will be important to understand in more mechanistic terms how cohesin contributes to gene regulation. Because cohesin is able to mediate cohesion between two sister chromatids-i.e., to physically connect two DNA molecules in trans-cohesin might also be able to connect two distant DNA elements on the same chromosome in cis. Such an arrangement would result in the formation of chromatin loops that could control interactions between promoter and enhancer sequences topologically. There is evidence from chromosome conformation capture (3C) experiments that CTCF is required for the formation of chromatin loops (Kurukuti et al. 2006; Splinter et al. 2006). However, since CTCF depletion also leads to disappearance of cohesin from CTCF sites (Parelho et al. 2008; Wendt et al. 2008) it is possible that cohesin is the molecule that structures DNA, whereas the main function of CTCF might be to target cohesin to particular regulatory sequences in the genome. It will therefore be interesting to test whether cohesin has a direct role in the formation of chromatin loops.

Another possibility is that cohesin interferes directly with transcription factors or chromatin-modifying enzymes by physically blocking their processive translocation along DNA. Such a situation may exist in fission yeast, where the accumulation of cohesin downstream from active genes promotes the termination of transcription that is catalyzed by RNA polymerase II /Gullerova and Proudfoot 2008). In this case, the RNAi pathway has been shown to induce the assembly of heterochromatic domains in the $3^{\prime}$ regions of active genes. Cohesin is recruited to these domains by a Swi6-dependent mechanism and is necessary to prevent read-through transcription from one gene into the next.

Whether cohesin also cooperates with CTCF in species other than mammals is not clear. In Drosophila, a CTCF ortholog has been identified, but the current evidence indicates that this protein does not colocalize with cohesin (Holohan et al. 2007; Misulovin et al. 2008; Pauli et al. 2008), and no CTCF orthologs have been identified in yeast so far. It is therefore possible that the roles of cohesin in controlling enhancer-promoter interactions in Drosophila and boundary functions in budding yeast are mediated either by cohesin alone, or by interactions between cohesin and other chromatin regulators.

\section{Cohesinopathies}

Defects in cohesin function have been linked to several human diseases that are therefore also referred to as "cohesinopathies." The most frequent of these diseases is Down syndrome (trisomy 21), which in the majority of cases is caused by missegregation ("nondisjunction") of chromosome 21 during meiosis I in oocytes (Hassold and Hunt 2001; Gilliland and Hawley 2005). Other trisomies are thought to occur with similar frequencies during meiosis, but with the extremely rare exceptions of trisomies 13 and 18, these situations are lethal during embryogenesis. As women age, the frequency with which nondisjunctions occur in oocytes increases dramatically. 
This maternal age effect correlates with an increased frequency of unpaired (univalent) chromosomes and precociously separated sister chromatids that can be observed in oocytes, suggesting that defects in sister chromatid cohesion may be one of the major causes of nondisjunction (Angell 1995; Wolstenholme and Angell 2000; Pellestor et al. 2003, 2006). Experimental support for this hypothesis comes from the observation that mice in which the meiosis-specific $S m c 1 \beta$ gene has been mutated show age-related defects in oocytes that mimic the situation observed in humans (Hodges et al. 2005). It is therefore possible that defects in cohesin or cohesin regulators are a major cause of Down syndrome. How these defects may occur, and why they would be agerelated, is unclear. However, it is interesting to note that in budding yeast cohesion can normally only be established during DNA replication (see above). If the same were true for mammalian oocytes, where cohesion is established during premeiotic DNA replication during prenatal development, cohesion would have to be able to persist for many years or even decades. Whether cohesin subunits can be dynamically exchanged during this long period (for example, by Scc2/Scc4 and Wapl-mediated mechanisms), or whether cohesion can be established de novo (as is the case in yeast under certain conditions), remains unknown. In either case, it is conceivable that cohesion slowly deteriorates over time and that the frequency of nondisjunction events therefore increases with age.

The high frequency with which aneuploidy can be observed in human oocytes and the age dependency of this phenomenon imply that mutations in cohesin genes are not or are only rarely responsible for nondisjunction events. However, Cornelia de Lange and Roberts/SC phocomelia syndrome have been linked recently to hypomorphic mutations in genes of cohesin subunits or regulators. Cornelia de Lange syndrome is characterized by growth defects, various developmental abnormalities, and mental retardation (for review, see Dorsett and Krantz 2008). About half of all investigated cases are caused by loss-of-function mutations in one allele of the NIPBL gene, the human ortholog of Scc2 (Krantz et al. 2004; Tonkin et al. 2004), and a few cases have been identified in which the genes encoding Smc1 and Smc3 have been mutated (Musio et al. 2006; Deardorff et al. 2007). Because sister chromatid cohesion is largely normal in cells derived from these patients, a defect in another cohesin function such as gene regulation may be the cause of the disease.

Roberts/SC phocomelia syndrome is also characterized by developmental defects, although the syndrome is clinically distinct from Cornelia de Lange syndrome (for review, see Dorsett 2007). Roberts/SC phocomelia syndrome has been linked to mutations in Esco2 (Schule et al. 2005; Vega et al. 2005), and consistent with the suspected role of this enzyme in cohesion establishment, defects in centromeric cohesion have been observed in cells derived from Roberts syndrome patients (German 1979; Tomkins et al. 1979). Whether these cohesion defects are the direct cause of the disease, or if defects in possible other functions of Esco2 are more relevant, is still unknown.

\section{Outlook}

Over the last decade, research on cohesin complexes has provided important insight into surprisingly many aspects of chromosome biology. Although cohesin was discovered as a protein that is required for sister chromatid cohesion in mitotic and meiotic cells, more recent work has revealed that understanding cohesin function will likewise be essential for the elucidation of DNA damage response pathways, mechanisms of gene regulation, and the etiology of several human diseases, possibly including the frequent Down syndrome. Studying how cohesin interacts with DNA at the mechanistic level will be of equal importance and may provide insight into how DNA has been organized since the early days of evolution, long before DNA was wrapped around nucleosomes. In particular, understanding whether and how the cohesin ring opens and closes when it interacts with DNA will remain a fascinating task for some time to come.

\section{Acknowledgments}

We thank Tatsuya Hirano, Péter Lénárt, Stephanie Kueng, Erwan Watrin, and Gordana Wutz for kindly providing images. Research in the laboratory of J.-M.P. is supported by Boehringer Ingelheim, the 6th Framework Programme of the European Union via the Integrated Project MitoCheck, and the Austrian Science Fund via the special research program Chromosome Dynamics.

\section{References}

Akhmedov, A.T., Gross, B., and Jessberger, R. 1999. Mammalian SMC3 C-terminal and coiled-coil protein domains specifically bind palindromic DNA, do not block DNA ends, and prevent DNA bending. J. Biol. Chem. 274: 38216-38224.

Alexandru, G., Uhlmann, F., Mechtler, K., Poupart, M., and Nasmyth, K. 2001. Phosphorylation of the cohesin subunit scc1 by polo/cdc5 kinase regulates sister chromatid separation in yeast. Cell 105: 459-472.

Anderson, D.E., Losada, A., Erickson, H.P., and Hirano, T. 2002. Condensin and cohesin display different arm conformations with characteristic hinge angles. J. Cell Biol. 156: 419-424.

Angell, R.R. 1995. Meiosis I in human oocytes. Cytogenet. Cell Genet. 69: 266-272.

Arumugam, P., Gruber, S., Tanaka, K., Haering, C.H., Mechtler, K., and Nasmyth, K. 2003. ATP hydrolysis is required for cohesin's association with chromosomes. Curr. Biol. 13: 1941-1953.

Baetz, K.K., Krogan, N.J., Emili, A., Greenblatt, J., and Hieter, P. 2004. The ctf13-30/CTF13 genomic haploinsufficiency modifier screen identifies the yeast chromatin remodeling complex RSC, which is required for the establishment of sister chromatid cohesion. Mol. Cell. Biol. 24: 1232-1244.

Bailis, J.M., Bernard, P., Antonelli, R., Allshire, R.C., and Forsburg, S.L. 2003. Hsk1-Dfp1 is required for heterochromatinmediated cohesion at centromeres. Nat. Cell Biol. 5: 11111116. 
Bannister, A.J., Zegerman, P., Partridge, J.F., Miska, E.A., Thomas, J.O., Allshire, R.C., and Kouzarides, T. 2001. Selective recognition of methylated lysine 9 on histone $\mathrm{H} 3$ by the HP1 chromo domain. Nature 410: 120-124.

Bartolomei, M.S. and Tilghman, S.M. 1997. Genomic imprinting in mammals. Annu. Rev. Genet. 31: 493-525.

Bausch, C., Noone, S., Henry, J.M., Gaudenz, K., Sanderson, B., Seidel, C., and Gerton, J.L. 2007. Transcription alters chromosomal locations of cohesin in S. cerevisiae. Mol. Cell. Biol. 27: 8522-8532.

Bell, A.C. and Felsenfeld, G. 2000. Methylation of a CTCF-dependent boundary controls imprinted expression of the Igf 2 gene. Nature 405: 482-485.

Benard, C.Y., Kebir, H., Takagi, S., and Hekimi, S. 2004. mau-2 acts cell-autonomously to guide axonal migrations in Caenorhabditis elegans. Development 131: 5947-5958.

Ben-Shahar, T.R., Heeger, S., Lehane, C., East, P., Flynn, H., Skehel, M., and Uhlmann, F. 2008. Ecol-dependent cohesin acetylation during establishment of sister chromatid cohesion. Science 321: 563-566.

Bernard, P., Maure, J.F., Partridge, J.F., Genier, S., Javerzat, J.P., and Allshire, R.C. 2001. Requirement of heterochromatin for cohesion at centromeres. Science 294: 2539-2542.

Bernard, P., Drogat, J., Maure, J.F., Dheur, S., Vaur, S., Genier, S., and Javerzat, J.P. 2006. A screen for cohesion mutants uncovers Ssl3, the fission yeast counterpart of the cohesin loading factor Scc4. Curr. Biol. 16: 875-881.

Bernard, P., Schmidt, C.K., Vaur, S., Dheur, S., Drogat, J., Genier, S., Ekwall, K., Uhlmann, F., and Javerzat, J.P. 2008. Cell-cycle regulation of cohesin stability along fission yeast chromosomes. EMBO J. 27: 111-121.

Bickel, S.E., Wyman, D.W., Miyazaki, W.Y., Moore, D.P., and Orr-Weaver, T.L. 1996. Identification of ORD, a Drosophila protein essential for sister chromatid cohesion. EMBO J. 15: 1451-1459.

Birkenbihl, R.P. and Subramani, S. 1992. Cloning and characterization of rad21 an essential gene of Schizosaccharomyces pombe involved in DNA double-strand-break repair. Nucleic Acids Res. 20: 6605-6611.

Blat, Y. and Kleckner, N. 1999. Cohesins bind to preferential sites along yeast chromosome III, with differential regulation along arms versus the centric region. Cell 98: 249-259.

Brar, G.A., Kiburz, B.M., Zhang, Y., Kim, J.E., White, F., and Amon, A. 2006. Rec8 phosphorylation and recombination promote the step-wise loss of cohesins in meiosis. Nature 441: 532-536.

Britton, R.A., Lin, D.C., and Grossman, A.D. 1998. Characterization of a prokaryotic SMC protein involved in chromosome partitioning. Genes \& Dev. 12: 1254-1259.

Buonomo, S.B., Clyne, R.K., Fuchs, J., Loidl, J., Uhlmann, F., and Nasmyth, K. 2000. Disjunction of homologous chromosomes in meiosis I depends on proteolytic cleavage of the meiotic cohesin Rec8 by separin. Cell 103: 387-398.

Canudas, S., Houghtaling, B.R., Kim, J.Y., Dynek, J.N., Chang, W.G., and Smith, S. 2007. Protein requirements for sister telomere association in human cells. $E M B O$ J. 26: 4867-4878.

Chang, C.R., Wu, C.S., Hom, Y., and Gartenberg, M.R. 2005. Targeting of cohesin by transcriptionally silent chromatin. Genes \& Dev. 19: 3031-3042.

Chang, P., Coughlin, M., and Mitchison, T.J. 2005. Tankyrase-1 polymerization of poly(ADP-ribose) is required for spindle structure and function. Nat. Cell Biol. 7: 1133-1139.

Chen, J., Lu, G., Lin, J., Davidson, A.L., and Quiocho, F.A. 2003. A tweezers-like motion of the ATP-binding cassette dimer in an ABC transport cycle. Mol. Cell 12: 651-661.
Ciosk, R., Shirayama, M., Shevchenko, A., Tanaka, T., Toth, A., and Nasmyth, K. 2000. Cohesin's binding to chromosomes depends on a separate complex consisting of Scc2 and Scc4 proteins. Mol. Cell 5: 243-254.

Clarke, L. and Carbon, J. 1985. The structure and function of yeast centromeres. Annu. Rev. Genet. 19: 29-55.

Dai, J., Sullivan, B.A., and Higgins, J.M. 2006. Regulation of mitotic chromosome cohesion by Haspin and Aurora B. Dev. Cell 11: 741-750.

Darwiche, N., Freeman, L.A., and Strunnikov, A. 1999. Characterization of the components of the putative mammalian sister chromatid cohesion complex. Gene 233: 39-47.

Davis, B.K. 1971. Genetic analysis of a meiotic mutant resulting in precocious sister centromere separation. Mol. Gen. Genet. 113: 251-272.

Deardorff, M.A., Kaur, M., Yaeger, D., Rampuria, A., Korolev, S., Pie, J., Gil-Rodriguez, C., Arnedo, M., Loeys, B., Kline, A.D., et al. 2007. Mutations in cohesin complex members SMC3 and SMC1A cause a mild variant of cornelia de Lange syndrome with predominant mental retardation. Am. I. Hum. Genet. 80: 485-494.

Denison, S.H., Käfer, E., and May, G.S. 1993. Mutation in the bimD gene of Aspergillus nidulans confers a conditional mitotic block and sensitivity to DNA damaging agents. Genetics 134: 1085-1096.

Diaz-Martinez, L.A., Gimenez-Abian, J.F., and Clarke, D.J. 2007a. Cohesin is dispensable for centromere cohesion in human cells. PLoS One 2: e318. doi: 10.1371/journal. pone.0000318.

Diaz-Martinez, L.A., Gimenez-Abian, J.F., and Clarke, D.J. 2007b. Regulation of centromeric cohesion by sororin independently of the APC/C. Cell Cycle 6: 714-724.

DiNardo, S., Voelkel, K., and Sternglanz, R. 1984. DNA topoisomerase II mutant of Saccharomyces cerevisiae: Topoisomerase II is required for segregation of daughter molecules at the termination of DNA replication. Proc. Nat1. Acad. Sci. 81: 2616-2620.

Donze, D., Adams, C.R., Rine, J., and Kamakaka, R.T. 1999. The boundaries of the silenced HMR domain in Saccharomyces cerevisiae. Genes \& Dev. 13: 698-708.

Dorsett, D. 2007. Roles of the sister chromatid cohesion apparatus in gene expression, development, and human syndromes. Chromosoma 116: 1-13.

Dorsett, D. and Krantz, I. 2008. On the molecular etiology of Cornelia de Lange Syndrome. Ann. N. Y. Acad. Sci. (in press).

Dorsett, D., Eissenberg, J.C., Misulovin, Z., Martens, A., Redding, B., and McKim, K. 2005. Effects of sister chromatid cohesion proteins on cut gene expression during wing development in Drosophila. Development 132: 4743-4753.

Dubey, R.N. and Gartenberg, M.R. 2007. A tDNA establishes cohesion of a neighboring silent chromatin domain. Genes \& Dev. 21: 2150-2160.

Dynek, J.N. and Smith, S. 2004. Resolution of sister telomere association is required for progression through mitosis. Science 304: 97-100.

Eckert, C.A., Gravdahl, D.J., and Megee, P.C. 2007. The enhancement of pericentromeric cohesin association by conserved kinetochore components promotes high-fidelity chromosome segregation and is sensitive to microtubule-based tension. Genes \& Dev. 21: 278-291.

Edwards, S., Li, C.M., Levy, D.L., Brown, J., Snow, P.M., and Campbell, J.L. 2003. Saccharomyces cerevisiae DNA polymerase $\varepsilon$ and polymerase $\sigma$ interact physically and functionally, suggesting a role for polymerase $\varepsilon$ in sister chromatid cohesion. Mol. Cell. Biol. 23: 2733-2748.

Farina, A., Shin, J.H., Kim, D.H., Bermudez, V.P., Kelman, Z., 
Seo, Y.S., and Hurwitz, J. 2008. Studies with the Human Cohesin Establishment Factor, ChlR1: Association of ChlR1 with Ctf18-RFC and Fen1. J. Biol. Chem. 283: 20925-20936.

Fukagawa, T., Nogami, M., Yoshikawa, M., Ikeno, M., Okazaki, T., Takami, Y., Nakayama, T., and Oshimura, M. 2004. Dicer is essential for formation of the heterochromatin structure in vertebrate cells. Nat. Cell Biol. 6: 784-791.

Funabiki, H., Yamano, H., Kumada, K., Nagao, K., Hunt, T., and Yanagida, M. 1996. Cut2 proteolysis required for sister-chromatid seperation in fission yeast. Nature 381: 438-441.

Furuya, K., Takahashi, K., and Yanagida, M. 1998. Faithful anaphase is ensured by Mis4, a sister chromatid cohesion molecule required in $\mathrm{S}$ phase and not destroyed in G1 phase. Genes \& Dev. 12: 3408-3418.

Game, J.C., Birrell, G.W., Brown, J.A., Shibata, T., Baccari, C. Chu, A.M., Williamson, M.S., and Brown, J.M. 2003. Use of a genome-wide approach to identify new genes that control resistance of Saccharomyces cerevisiae to ionizing radiation. Radiat. Res. 160: 14-24.

Gandhi, R., Gillespie, P.J., and Hirano, T. 2006. Human Wapl is a cohesin-binding protein that promotes sister-chromatid resolution in mitotic prophase. Curr. Biol. 16: 2406-2417.

Garg, R., Callens, S., Lim, D.S., Canman, C.E., Kastan, M.B., and $\mathrm{Xu}, \mathrm{B} .2004$. Chromatin association of $\operatorname{rad} 17$ is required for an ataxia telangiectasia and rad-related kinase-mediated Sphase checkpoint in response to low-dose ultraviolet radiation. Mol. Cancer Res. 2: 362-369.

Gause, M., Webber, H.A., Misulovin, Z., Haller, G., Rollins, R.A., Eissenberg, J.C., Bickel, S.E., and Dorsett, D. 2008. Functional links between Drosophila Nipped-B and cohesin in somatic and meiotic cells. Chromosoma 117: 51-66.

Gerlich, D., Koch, B., Dupeux, F., Peters, J.M., and Ellenberg, J. 2006. Live-cell imaging reveals a stable cohesin-chromatin interaction after but not before DNA replication. Curr. Biol. 16: $1571-1578$.

German, J. 1979. Roberts' syndrome. I. Cytological evidence for a disturbance in chromatid pairing. Clin. Genet. 16: 441447.

Gillespie, P.J. and Hirano, T. 2004. Scc2 couples replication licensing to sister chromatid cohesion in Xenopus egg extracts. Curr. Biol. 14: 1598-1603.

Gilliland, W.D. and Hawley, R.S. 2005. Cohesin and the maternal age effect. Cell 123: 371-373.

Gimenez-Abian, J.F., Sumara, I., Hirota, T., Hauf, S., Gerlich, D., de la Torre, C., Ellenberg, J., and Peters, J.M. 2004. Regulation of sister chromatid cohesion between chromosome arms. Curr. Biol. 14: 1187-1193.

Glynn, E.F., Megee, P.C., Yu, H.G., Mistrot, C., Unal, E., Koshland, D.E., DeRisi, J.L., and Gerton, J.L. 2004. Genome-wide mapping of the cohesin complex in the yeast Saccharomyces cerevisiae. PLoS Biol. 2: E259. doi: 10.1371/journal. pbio.0020259.

Gorr, I.H., Boos, D., and Stemmann, O. 2005. Mutual inhibition of separase and Cdk1 by two-step complex formation. Mol. Cell 19: 135-141.

Goshima, G. and Yanagida, M. 2000. Establishing biorientation occurs with precocious separation of the sister kinetochores, but not the arms, in the early spindle of budding yeast. Cell 100: 619-633.

Gruber, S., Haering, C.H., and Nasmyth, K. 2003. Chromosomal cohesin forms a ring. Cell 112: 765-777.

Gruber, S., Arumugam, P., Katou, Y., Kuglitsch, D., Helmhart, W., Shirahige, K., and Nasmyth, K. 2006. Evidence that loading of cohesin onto chromosomes involves opening of its SMC hinge. Cell 127: 523-537.

Guacci, V., Hogan, E., and Koshland, D. 1994. Chromosome condensation and sister chromatid pairing in budding yeast. J. Cell Biol. 125: 517-530.

Guacci, V., Koshland, D., and Strunnikov, A. 1997. A direct link between sister chromatid cohesion and chromosome condensation revealed through the analysis of MCD1 in $S$. cerevisiae. Cell 91: 47-57.

Guenatri, M., Bailly, D., Maison, C., and Almouzni, G. 2004. Mouse centric and pericentric satellite repeats form distinct functional heterochromatin. J. Cell Biol. 166: 493-505.

Gullerova, M. and Proudfoot, N.J. 2008. Cohesin complex promotes transcriptional termination between convergent genes in S. pombe. Cell 132: 983-995.

Haering, C.H., Lowe, J., Hochwagen, A., and Nasmyth, K. 2002. Molecular architecture of SMC proteins and the yeast cohesin complex. Mol. Cell 9: 773-788.

Haering, C.H., Schoffnegger, D., Nishino, T., Helmhart, W., Nasmyth, K., and Lowe, J. 2004. Structure and stability of cohesin's Smcl-kleisin interaction. Mol. Cell 15: 951-964.

Haering, C.H., Farcas, A.M., Arumugam, P., Metson, J., and Nasmyth, K. 2008. The cohesin ring concatenates sister DNA molecules. Nature 454: 297-301.

Hakimi, M.A., Bochar, D.A., Schmiesing, J.A., Dong, Y., Barak, O.G., Speicher, D.W., Yokomori, K., and Shiekhattar, R. 2002. A chromatin remodelling complex that loads cohesin onto human chromosomes. Nature 418: 994-998.

Hall, I.M., Noma, K., and Grewal, S.I. 2003. RNA interference machinery regulates chromosome dynamics during mitosis and meiosis in fission yeast. Proc. Nat1. Acad. Sci. 100: 193198.

Hamant, O., Golubovskaya, I., Meeley, R., Fiume, E., Timofejeva, L., Schleiffer, A., Nasmyth, K., and Cande, W.Z. 2005. A REC8-dependent plant Shugoshin is required for maintenance of centromeric cohesion during meiosis and has no mitotic functions. Curr. Biol. 15: 948-954.

Hark, A.T., Schoenherr, C.J., Katz, D.J., Ingram, R.S., Levorse, J.M., and Tilghman, S.M. 2000. CTCF mediates methylation-sensitive enhancer-blocking activity at the H19/Igf2 locus. Nature 405: 486-489.

Hartman, T., Stead, K., Koshland, D., and Guacci, V. 2000. $\mathrm{Pds} 5 \mathrm{p}$ is an essential chromosomal protein required for both sister chromatid cohesion and condensation in Saccharomyces cerevisiae. J. Cell Biol. 151: 613-626.

Hassold, T. and Hunt, P. 2001. To err (meiotically) is human: The genesis of human aneuploidy. Nat. Rev. Genet. 2: 280291.

Hauf, S., Waizenegger, I.C., and Peters, J.M. 2001. Cohesin cleavage by separase required for anaphase and cytokinesis in human cells. Science 293: 1320-1323.

Hauf, S., Roitinger, E., Koch, B., Dittrich, C.M., Mechtler, K., and Peters, J.M. 2005. Dissociation of cohesin from chromosome arms and loss of arm cohesion during early mitosis depends on phosphorylation of SA2. PLoS Biol. 3: 419-432.

He, X., Asthana, S., and Sorger, P.K. 2000. Transient sister chromatid separation and elastic deformation of chromosomes during mitosis in budding yeast. Cell 101: 763-775.

Heidinger-Pauli, J.M., Unal, E., Guacci, V., and Koshland, D. 2008. The kleisin subunit of cohesin dictates damage-induced cohesion. Mol. Cell 31: 47-56.

Heidmann, D., Horn, S., Heidmann, S., Schleiffer, A., Nasmyth, K., and Lehner, C.F. 2004. The Drosophila meiotic kleisin $\mathrm{C}(2) \mathrm{M}$ functions before the meiotic divisions. Chromosoma 113: $177-187$.

Hirano, M. and Hirano, T. 2002. Hinge-mediated dimerization of SMC protein is essential for its dynamic interaction with DNA. EMBO I. 21: 5733-5744.

Hirano, M. and Hirano, T. 2006. Opening closed arms: Long- 
distance activation of SMC ATPase by hinge-DNA interactions. Mol. Cell 21: 175-186.

Hirota, T., Gerlich, D., Koch, B., Ellenberg, J., and Peters, J.M. 2004. Distinct functions of condensin I and II in mitotic chromosome assembly. J. Cell Sci. 117: 6435-6445.

Hodges, C.A., Revenkova, E., Jessberger, R., Hassold, T.J., and Hunt, P.A. 2005. SMC1 $\beta$-deficient female mice provide evidence that cohesins are a missing link in age-related nondisjunction. Nat. Genet. 37: 1351-1355.

Holohan, E.E., Kwong, C., Adryan, B., Bartkuhn, M., Herold, M., Renkawitz, R., Russell, S., and White, R. 2007. CTCF genomic binding sites in Drosophila and the organisation of the bithorax complex. PLoS Genet. 3: e112. doi: 10.1371/ journal.pgen.0030112.

Holt, C.L. and May, G.S. 1996. An extragenic suppressor of the mitosis-defective bimD6 mutation of Aspergillus nidulans codes for a chromosome scaffold protein. Genetics 142: $777-$ 787.

Holt, S.V., Vergnolle, M.A., Hussein, D., Wozniak, M.J., Allan, V.J., and Taylor, S.S. 2005. Silencing Cenp-F weakens centromeric cohesion, prevents chromosome alignment and activates the spindle checkpoint. J. Cell Sci. 118: 4889-4900.

Hopfner, K.P., Karcher, A., Shin, D.S., Craig, L., Arthur, L.M., Carney, J.P., and Tainer, J.A. 2000. Structural biology of Rad50 ATPase: ATP-driven conformational control in DNA double-strand break repair and the ABC-ATPase superfamily. Cell 101: 789-800.

Hopfner, K.P., Craig, L., Moncalian, G., Zinkel, R.A., Usui, T., Owen, B.A., Karcher, A., Henderson, B., Bodmer, J.L., McMurray, C.T., et al. 2002. The Rad50 zinc-hook is a structure joining Mre11 complexes in DNA recombination and repair. Nature 418: 562-566.

Hoque, M.T. and Ishikawa, F. 2000. Human chromatid cohesin component hRad21 is phosphorylated in $\mathrm{M}$ phase and associated with metaphase centromeres. J. Biol. Chem. 276: 5059-5067.

Hoque, M.T. and Ishikawa, F. 2002. Cohesin defects lead to premature sister chromatid separation, kinetochore dysfunction, and spindle-assembly checkpoint activation. J. Biol. Chem. 277: 42306-42314.

Hornig, N.C. and Uhlmann, F. 2004. Preferential cleavage of chromatin-bound cohesin after targeted phosphorylation by Polo-like kinase. EMBO J. 23: 3144-3153.

Hornig, N.C., Knowles, P.P., McDonald, N.Q., and Uhlmann, F. 2002. The dual mechanism of separase regulation by securin. Curr. Biol. 12: 973-982.

Horsfield, J.A., Anagnostou, S.H., Hu, J.K., Cho, K.H., Geisler, R., Lieschke, G., Crosier, K.E., and Crosier, P.S. 2007. Cohesin-dependent regulation of Runx genes. Development 134: 2639-2649.

Hou, F. and Zou, H. 2005. Two human orthologues of Eco1/Ctf7 acetyltransferases are both required for proper sister-chromatid cohesion. Mol. Biol. Cell 16: 3908-3918.

Hou, F., Chu, C.W., Kong, X., Yokomori, K., and Zou, H. 2007. The acetyltransferase activity of San stabilizes the mitotic cohesin at the centromeres in a shugoshin-independent manner. J. Cell Biol. 177: 587-597.

Hu, D., Valentine, M., Kidd, V.J., and Lahti, J.M. 2007. CDK11p58 is required for the maintenance of sister chromatid cohesion. J. Cell Sci. 120: 2424-2434.

Huang, J., Hsu, J.M., and Laurent, B.C. 2004. The RSC nucleosome-remodeling complex is required for Cohesin's association with chromosome arms. Mol. Cell 13: 739-750.

Huang, C.E., Milutinovich, M., and Koshland, D. 2005. Rings, bracelet or snaps: Fashionable alternatives for Smc complexes. Philos. Trans. R. Soc. Lond. B Biol. Sci. 360: 537-542.
Huang, X., Hatcher, R., York, J.P., and Zhang, P. 2005. Securin and separase phosphorylation act redundantly to maintain sister chromatid cohesion in mammalian cells. Mol. Biol. Cell 16: 4725-4732.

Huang, X., Andreu-Vieyra, C.V., York, J.P., Hatcher, R., Lu, T., Matzuk, M.M., and Zhang, P. 2008. Inhibitory phosphorylation of separase is essential for genome stability and viability of murine embryonic germ cells. PLoS Biol. 6: e15. doi: 10.1371/journal.pbio.0060015.

Inoue, A., Hyle, J., Lechner, M.S., and Lahti, J.M. 2008. Perturbation of HP1 localization and chromatin binding ability causes defects in sister-chromatid cohesion. Mutat. Res. doi: 10.1016/j.mrgentox.2008.08.010.

Ivanov, D. and Nasmyth, K. 2005. A topological interaction between cohesin rings and a circular minichromosome. Cell 122: $849-860$.

Ivanov, D. and Nasmyth, K. 2007. A physical assay for sister chromatid cohesion in vitro. Mol. Cell 27: 300-310.

Ivanov, D., Schleiffer, A., Eisenhaber, F., Mechtler, K., Haering, C.H., and Nasmyth, K. 2002. Eco1 is a novel acetyltransferase that can acetylate proteins involved in cohesion. Curr. Biol. 12: 323-328.

Jager, H., Herzig, A., Lehner, C.F., and Heidmann, S. 2001. Drosophila separase is required for sister chromatid separation and binds to PIM and THR. Genes \& Dev. 15: 2572-2584.

Jessberger, R., Riwar, B., Baechtold, H., and Akhmedov, A.T. 1996. SMC proteins constitute two subunits of the mammalian recombination complex RC-1. EMBO J. 15: 4061-4068.

Kagansky, A., Freeman, L., Lukyanov, D., and Strunnikov, A. 2004. Histone tail-independent chromatin binding activity of recombinant cohesin holocomplex. J. Biol. Chem. 279: 3382-3388.

Katis, V.L., Galova, M., Rabitsch, K.P., Gregan, J., and Nasmyth, K. 2004. Maintenance of cohesin at centromeres after meiosis I in budding yeast requires a kinetochore-associated protein related to MEI-S332. Curr. Biol. 14: 560-572.

Kenna, M.A. and Skibbens, R.V. 2003. Mechanical link between cohesion establishment and DNA replication: Ctf7p/Ecolp, a cohesion establishment factor, associates with three different replication factor C complexes. Mol. Cell. Biol. 23: 2999-3007.

Kerrebrock, A.W., Miyazaki, W.Y., Birnby, D., and Orr Weaver, T.L. 1992. The Drosophila mei-S332 gene promotes sisterchromatid cohesion in meiosis following kinetochore differentiation. Genetics 130: 827-841.

Khetani, R.S. and Bickel, S.E. 2007. Regulation of meiotic cohesion and chromosome core morphogenesis during pachytene in Drosophila oocytes. J. Cell Sci. 120: 3123-3137.

Kiburz, B.M., Reynolds, D.B., Megee, P.C., Marston, A.L., Lee, B.H., Lee, T.I., Levine, S.S., Young, R.A., and Amon, A. 2005. The core centromere and Sgol establish a 50-kb cohesinprotected domain around centromeres during meiosis I. Genes \& Dev. 19: 3017-3030.

Kim, S.T., Xu, B., and Kastan, M.B. 2002. Involvement of the cohesin protein, $\mathrm{Smc1}$, in Atm-dependent and independent responses to DNA damage. Genes \& Dev. 16: 560-570.

Kitagawa, R., Bakkenist, C.J., McKinnon, P.J., and Kastan, M.B. 2004. Phosphorylation of SMC1 is a critical downstream event in the ATM-NBS1-BRCA1 pathway. Genes \& Dev. 18: 1423-1438.

Kitajima, T.S., Yokobayashi, S., Yamamoto, M., and Watanabe, Y. 2003a. Distinct cohesin complexes organize meiotic chromosome domains. Science 300: 1152-1155.

Kitajima, T.S., Miyazaki, Y., Yamamoto, M., and Watanabe, Y. 2003b. Rec8 cleavage by separase is required for meiotic nuclear divisions in fission yeast. EMBO J. 22: 5643-5653. 
Kitajima, T.S., Kawashima, S.A., and Watanabe, Y. 2004. The conserved kinetochore protein shugoshin protects centromeric cohesion during meiosis. Nature 427: 510-517.

Kitajima, T.S., Hauf, S., Ohsugi, M., Yamamoto, T., and Watanabe, Y. 2005. Human Bub1 defines the persistent cohesion site along the mitotic chromosome by affecting Shugoshin localization. Curr. Biol. 15: 353-359.

Kitajima, T.S., Sakuno, T., Ishiguro, K., Iemura, S., Natsume, T., Kawashima, S.A., and Watanabe, Y. 2006. Shugoshin collaborates with protein phosphatase $2 \mathrm{~A}$ to protect cohesin. Nature 441: 46-52.

Klein, F., Mahr, P., Galova, M., Buonomo, S.B., Michaelis, C., Nairz, K., and Nasmyth, K. 1999. A central role for cohesins in sister chromatid cohesion, formation of axial elements, and recombination during yeast meiosis. Cell 98: 91-103.

Koch, B., Kueng, S., Ruckenbauer, C., Wendt, K.S., and Peters, J.M. 2007. The Suv39h-HP1 histone methylation pathway is dispensable for enrichment and protection of cohesin at centromeres in mammalian cells. Chromosoma 117: 199-210.

Koshland, D. and Hartwell, L. 1987. The structure of sister minichromosome DNA before anaphase in Saccharomyces cerevisiae. Science 238: 1713-1716.

Krantz, I.D., McCallum, J., DeScipio, C., Kaur, M., Gillis, L.A., Yaeger, D., Jukofsky, L., Wasserman, N., Bottani, A., Morris, C.A., et al. 2004. Cornelia de Lange syndrome is caused by mutations in NIPBL, the human homolog of Drosophila melanogaster Nipped-B. Nat. Genet. 36: 631-635.

Kudo, N.R., Wassmann, K., Anger, M., Schuh, M., Wirth, K.G., Xu, H., Helmhart, W., Kudo, H., McKay, M., Maro, B., et al. 2006. Resolution of chiasmata in oocytes requires separasemediated proteolysis. Cell 126: 135-146.

Kueng, S., Hegemann, B., Peters, B.H., Lipp, J.J., Schleiffer, A., Mechtler, K., and Peters, J.M. 2006. Wapl controls the dynamic association of cohesin with chromatin. Cell 127: 955967.

Kumada, K., Yao, R., Kawaguchi, T., Karasawa, M., Hoshikawa, Y., Ichikawa, K., Sugitani, Y., Imoto, I., Inazawa, J., Sugawara, M., et al. 2006. The selective continued linkage of centromeres from mitosis to interphase in the absence of mammalian separase. J. Cell Biol. 172: 835-846.

Kurukuti, S., Tiwari, V.K., Tavoosidana, G., Pugacheva, E., Murrell, A., Zhao, Z., Lobanenkov, V., Reik, W., and Ohlsson, R. 2006. CTCF binding at the H19 imprinting control region mediates maternally inherited higher-order chromatin conformation to restrict enhancer access to Igf2. Proc. Nat1. Acad. Sci. 103: 10684-10689.

Laloraya, S., Guacci, V., and Koshland, D. 2000. Chromosomal addresses of the cohesin component Mcd1p. J. Cell Biol. 151: 1047-1056.

Lee, J., Kitajima, T.S., Tanno, Y., Yoshida, K., Morita, T., Miyano, T., Miyake, M., and Watanabe, Y. 2008. Unified mode of centromeric protection by shugoshin in mammalian oocytes and somatic cells. Nat. Cell Biol. 10: 42-52.

Lenart, P., Petronczki, M., Steegmaier, M., Di Fiore, B., Lipp, J.J., Hoffmann, M., Rettig, W.J., Kraut, N., and Peters, J.M. 2007. The small-molecule inhibitor BI 2536 reveals novel insights into mitotic roles of polo-like kinase 1. Curr. Biol. 17: 304315 .

Lengronne, A., Katou, Y., Mori, S., Yokobayashi, S., Kelly, G.P., Itoh, T., Watanabe, Y., Shirahige, K., and Uhlmann, F. 2004. Cohesin relocation from sites of chromosomal loading to places of convergent transcription. Nature 430: 573-578.

Lengronne, A., McIntyre, J., Katou, Y., Kanoh, Y., Hopfner, K.P., Shirahige, K., and Uhlmann, F. 2006. Establishment of sister chromatid cohesion at the S. cerevisiae replication fork. Mol. Cell 23: 787-799.
Lindroos, H.B., Ström, L., Itoh, T., Katou, Y., Shirahige, K., and Sjögren, C. 2006. Chromosomal association of the Smc5/6 complex reveals that it functions in differently regulated pathways. Mol. Cell 22: 755-767.

Lipp, J.J., Hirota, T., Poser, I., and Peters, J.M. 2007. Aurora B controls the association of condensin I but not condensin II with mitotic chromosomes. J. Cell Sci. 120: 1245-1255.

Losada, A. and Hirano, T. 2001. Intermolecular DNA interactions stimulated by the cohesin complex in vitro: Implications for sister chromatid cohesion. Curr. Biol. 11: 268-272.

Losada, A., Hirano, M., and Hirano, T. 1998. Identification of Xenopus SMC protein complexes required for sister chromatid cohesion. Genes \& Dev. 12: 1986-1997.

Losada, A., Yokochi, T., Kobayashi, R., and Hirano, T. 2000. Identification and characterization of SA/Scc3p subunits in the Xenopus and human cohesin complexes. J. Cell Biol. 150: 405-416.

Losada, A., Hirano, M., and Hirano, T. 2002. Cohesin release is required for sister chromatid resolution, but not for condensin-mediated compaction, at the onset of mitosis. Genes \& Dev. 16: 3004-3016.

Losada, A., Yokochi, T., and Hirano, T. 2005. Functional contribution of Pds5 to cohesin-mediated cohesion in human cells and Xenopus egg extracts. J. Cell Sci. 118: 2133-2141.

Luo, H., Li, Y., Mu, J.J., Zhang, J., Tonaka, T., Hamamori, Y., Jung, S.Y., Wang, Y., and Qin, J. 2008. Regulation of intra-S phase checkpoint by ionizing radiation (IR)-dependent and IR-independent phosphorylation of SMC3. J. Biol. Chem. 283: $19176-19183$.

Mann, M.B., Hodges, C.A., Barnes, E., Vogel, H., Hassold, T.J., and Luo, G. 2005. Defective sister-chromatid cohesion, aneuploidy and cancer predisposition in a mouse model of type II Rothmund-Thomson syndrome. Hum. Mol. Genet. 14: $813-825$

Marston, A.L. and Amon, A. 2004. Meiosis: Cell-cycle controls shuffle and deal. Nat. Rev. Mol. Cell Biol. 5: 983-997.

Marston, A.L., Tham, W.H., Shah, H., and Amon, A. 2004. A genome-wide screen identifies genes required for centromeric cohesion. Science 303: 1367-1370.

Mascarenhas, J., Soppa, J., Strunnikov, A.V., and Graumann, P.L. 2002. Cell cycle-dependent localization of two novel prokaryotic chromosome segregation and condensation proteins in Bacillus subtilis that interact with SMC protein. EMBO J. 21: 3108-3118.

Mayer, M.L., Gygi, S.P., Aebersold, R., and Hieter, P. 2001. Identification of RFC(Ctf18p, Ctf8p, Dcclp): An alternative RFC complex required for sister chromatid cohesion in $S$. cerevisiae. Mol. Cell 7: 959-970.

Mayer, M.L., Pot, I., Chang, M., Xu, H., Aneliunas, V., Kwok, T., Newitt, R., Aebersold, R., Boone, C., Brown, G.W., et al. 2004. Identification of protein complexes required for efficient sister chromatid cohesion. Mol. Biol. Cell 15: 17361745 .

McGuinness, B.E., Hirota, T., Kudo, N.R., Peters, J.M., and Nasmyth, K. 2005. Shugoshin prevents dissociation of cohesin from centromeres during mitosis in vertebrate cells. PLoS Biol. 3: 433-449.

Mc Intyre, J., Muller, E.G., Weitzer, S., Snydsman, B.E., Davis, T.N., and Uhlmann, F. 2007. In vivo analysis of cohesin architecture using FRET in the budding yeast Saccharomyces cerevisiae. EMBO J. 26: 3783-3793.

Megee, P.C., Mistrot, C., Guacci, V., and Koshland, D. 1999. The centromeric sister chromatid cohesion site directs Mcdlp binding to adjacent sequences. Mol. Cell 4: 445-450.

Melby, T.E., Ciampaglio, C.N., Briscoe, G., and Erickson, H.P. 1998. The symmetrical structure of structural maintenance 
of chromosomes (SMC) and MukB proteins: Long, antiparallel coiled coils, folded at a flexible hinge. J. Cell Biol. 142: 1595-1604.

Mendez, J. and Stillman, B. 2000. Chromatin association of human origin recognition complex, cdc6, and minichromosome maintenance proteins during the cell cycle: Assembly of prereplication complexes in late mitosis. Mol. Cell. Biol. 20: 8602-8612.

Michaelis, C., Ciosk, R., and Nasmyth, K. 1997. Cohesins: Chromosomal proteins that prevent premature separation of sister chromatids. Cell 91: 35-45.

Milutinovich, M., Unal, E., Ward, C., Skibbens, R.V., and Koshland, D. 2007. A multi-step pathway for the establishment of sister chromatid cohesion. PLoS Genet. 3: e12. doi: 10.1371/journal.pgen.0030012.

Misulovin, Z., Schwartz, Y.B., Li, X.Y., Kahn, T.G., Gause, M., MacArthur, S., Fay, J.C., Eisen, M.B., Pirrotta, V., Biggin, M.D., et al. 2008. Association of cohesin and Nipped-B with transcriptionally active regions of the Drosophila melanogaster genome. Chromosoma 117: 89-102.

Miyazaki, W.Y. and Orr-Weaver, T.L. 1992. Sister-chromatid misbehavior in Drosophila ord mutants. Genetics 132: 1047-1061.

Moldovan, G.L., Pfander, B., and Jentsch, S. 2006. PCNA controls establishment of sister chromatid cohesion during $\mathrm{S}$ phase. Mol. Cell 23: 723-732.

Moriya, S., Tsujikawa, E., Hassan, A.K., Asai, K., Kodama, T., and Ogasawara, N. 1998. A Bacillus subtilis gene-encoding protein homologous to eukaryotic SMC motor protein is necessary for chromosome partition. Mol. Microbiol. 29: $179-187$.

Murray, A.W. and Szostak, J.W. 1985. Chromosome segregation in mitosis and meiosis. Annu. Rev. Cell Biol. 1: 289-315.

Musio, A., Selicorni, A., Focarelli, M.L., Gervasini, C., Milani, D., Russo, S., Vezzoni, P., and Larizza, L. 2006. X-linked Cornelia de Lange syndrome owing to SMC1L1 mutations. Nat. Genet. 38: 528-530.

Nagao, K., Adachi, Y., and Yanagida, M. 2004. Separase-mediated cleavage of cohesin at interphase is required for DNA repair. Nature 430: 1044-1048.

Nakajima, M., Kumada, K., Hatakeyama, K., Noda, T., Peters, J.M., and Hirota, T. 2007. The complete removal of cohesin from chromosome arms depends on separase. J. Cell Sci. 120: 4188-4196.

Nakayama, J., Klar, A.J., and Grewal, S.I. 2000. A chromodomain protein, Swi6, performs imprinting functions in fission yeast during mitosis and meiosis. Cell 101: 307-317.

Nakayama, J., Rice, J.C., Strahl, B.D., Allis, C.D., and Grewal, S.I. 2001. Role of histone H3 lysine 9 methylation in epigenetic control of heterochromatin assembly. Science 292: $110-113$.

Nasmyth, K. 2005. How might cohesin hold sister chromatids together? Philos. Trans. R. Soc. Lond. B Biol. Sci. 360: 483496.

Nasmyth, K. and Haering, C.H. 2005. The structure and function of SMC and kleisin complexes. Annu. Rev. Biochem. 74: 595-648.

Nasmyth, K., Peters, J.M., and Uhlmann, F. 2000. Splitting the chromosome: Cutting the ties that bind sister chromatids. Science 288: 1379-1385.

Nonaka, N., Kitajima, T., Yokobayashi, S., Xiao, G., Yamamoto, M., Grewal, S.I., and Watanabe, Y. 2002. Recruitment of cohesin to heterochromatic regions by Swi6/HP1 in fission yeast. Nat. Cell Biol. 4: 89-93.

Ocampo-Hafalla, M.T., Katou, Y., Shirahige, K., and Uhlmann, F. 2007. Displacement and re-accumulation of centromeric cohesin during transient pre-anaphase centromere splitting. Chromosoma 116: 531-544.

Panizza, S., Tanaka, T., Hochwagen, A., Eisenhaber, F., and Nasmyth, K. 2000. Pds5 cooperates with cohesin in maintaining sister chromatid cohesion. Curr. Biol. 10: 1557-1564.

Papi, M., Berdougo, E., Randall, C.L., Ganguly, S., and Jallepalli, P.V. 2005. Multiple roles for separase auto-cleavage during the G2/M transition. Nat. Cell Biol. 7: 1029-1035.

Parelho, V., Hadjur, S., Spivakov, M., Leleu, M., Sauer, S., Gregson, H.C., Jarmuz, A., Canzonetta, C., Webster, Z., Nesterova, T., et al. 2008. Cohesins functionally associate with CTCF on mammalian chromosome arms. Cell 132: 422-433.

Parish, J.L., Rosa, J., Wang, X., Lahti, J.M., Doxsey, S.J., and Androphy, E.J. 2006. The DNA helicase ChlR1 is required for sister chromatid cohesion in mammalian cells. J. Cell Sci. 119: 4857-4865.

Partridge, J.F., Borgstrom, B., and Allshire, R.C. 2000. Distinct protein interaction domains and protein spreading in a complex centromere. Genes \& Dev. 14: 783-791.

Pasierbek, P., Jantsch, M., Melcher, M., Schleiffer, A., Schweizer, D., and Loidl, J. 2001. A Caenorhabditis elegans cohesion protein with functions in meiotic chromosome pairing and disjunction. Genes \& Dev. 15: 1349-1360.

Pauli, A., Althoff, F., Oliveira, R.A., Heidmann, S., Schuldiner, O., Lehner, C.F., Dickson, B.J., and Nasmyth, K. 2008. Celltype-specific TEV protease cleavage reveals cohesin functions in Drosophila neurons. Dev. Cell 14: 239-251.

Pellestor, F., Andreo, B., Arnal, F., Humeau, C., and Demaille, J. 2003. Maternal aging and chromosomal abnormalities: New data drawn from in vitro unfertilized human oocytes. Hum. Genet. 112: 195-203.

Pellestor, F., Andreo, B., Anahory, T., and Hamamah, S. 2006. The occurrence of aneuploidy in human: Lessons from the cytogenetic studies of human oocytes. Eur. J. Med. Genet. 49: 103-116.

Peng, J.C. and Karpen, G.H. 2007. H3K9 methylation and RNA interference regulate nucleolar organization and repeated DNA stability. Nat. Cell Biol. 9: 25-35.

Perera, D., Tilston, V., Hopwood, J.A., Barchi, M., Boot-Handford, R.P., and Taylor, S.S. 2007. Bub1 maintains centromeric cohesion by activation of the spindle checkpoint. Dev. Cell 13: 566-579.

Perrimon, N., Engstrom, L., and Mahowald, A.P. 1985. Developmental genetics of the 2C-D region of the Drosophila X chromosome. Genetics 111: 23-41.

Peters, J.M. 2002. The anaphase-promoting complex: Proteolysis in mitosis and beyond. Mol. Cell 9: 931-943.

Peters, J.M. 2006. The anaphase promoting complex/cyclosome: A machine designed to destroy. Nat. Rev. Mol. Cell Biol. 7: 644-656.

Petronczki, M., Siomos, M.F., and Nasmyth, K. 2003. Un menage a quatre: The molecular biology of chromosome segregation in meiosis. Cell 112: 423-440.

Petronczki, M., Chwalla, B., Siomos, M.F., Yokobayashi, S., Helmhart, W., Deutschbauer, A.M., Davis, R.W., Watanabe, Y., and Nasmyth, K. 2004. Sister-chromatid cohesion mediated by the alternative RF-CCtf18/Dcc1/Ctf8, the helicase $\mathrm{Chl} 1$ and the polymerase- $\alpha$-associated protein Ctf 4 is essential for chromatid disjunction during meiosis II. J. Cell Sci. 117: 3547-3559.

Pezzi, N., Prieto, I., Kremer, L., Perez Jurado, L.A., Valero, C., Del Mazo, J., Martinez, A.C., and Barbero, J.L. 2000. STAG3, a novel gene encoding a protein involved in meiotic chromosome pairing and location of STAG3-related genes flanking the Williams- Beuren syndrome deletion. FASEB J. 14: 581-592. 
Potts, P.R., Porteus, M.H., and Yu, H. 2006. Human SMC5/6 complex promotes sister chromatid homologous recombination by recruiting the $\mathrm{SMC} 1 / 3$ cohesin complex to doublestrand breaks. EMBO J. 25: 3377-3388.

Prieto, I., Suja, J.A., Pezzi, N., Kremer, L., Martinez, A.C., Rufas, J.S., and Barbero, J.L. 2001. Mammalian STAG3 is a cohesin specific to sister chromatid arms in meiosis I. Nat. Cell Biol. 3: 761-766.

Rabitsch, K.P., Gregan, J., Schleiffer, A., Javerzat, J.P., Eisenhaber, F., and Nasmyth, K. 2004. Two fission yeast homologs of Drosophila Mei-S332 are required for chromosome segregation during meiosis I and II. Curr. Biol. 14: 287-301.

Rankin, S., Ayad, N.G., and Kirschner, M.W. 2005. Sororin, a substrate of the anaphase-promoting complex, is required for sister chromatid cohesion in vertebrates. Mol. Cell 18: 185200.

Rao, H., Uhlmann, F., Nasmyth, K., and Varshavsky, A. 2001. Degradation of a cohesin subunit by the $\mathrm{N}$-end rule pathway is essential for chromosome stability. Nature 410: 955-959.

Rea, S., Eisenhaber, F., O'Carroll, D., Strahl, B.D., Sun, Z.W., Schmid, M., Opravil, S., Mechtler, K., Ponting, C.P., Allis, C.D., et al. 2000. Regulation of chromatin structure by sitespecific histone H3 methyltransferases. Nature 406: 593599.

Resnick, T.D., Satinover, D.L., Macisaac, F., Stukenberg, P.T., Earnshaw, W.C., Orr-Weaver, T.L., and Carmena, M. 2006. INCENP and Aurora B promote meiotic sister chromatid cohesion through localization of the shugoshin MEI-S332 in Drosophila. Dev. Cell 11: 57-68.

Revenkova, E., Eijpe, M., Heyting, C., Gross, B., and Jessberger, R. 2001. Novel meiosis-specific isoform of mammalian SMC1. Mol. Cell. Biol. 21: 6984-6998.

Revenkova, E., Eijpe, M., Heyting, C., Hodges, C.A., Hunt, P.A., Liebe, B., Scherthan, H., and Jessberger, R. 2004. Cohesin SMC1 $\beta$ is required for meiotic chromosome dynamics, sister chromatid cohesion and DNA recombination. Nat. Cell Biol. 6: 555-562.

Riedel, C.G., Gregan, J., Gruber, S., and Nasmyth, K. 2004. Is chromatin remodeling required to build sister-chromatid cohesion? Trends Biochem. Sci. 29: 389-392.

Riedel, C.G., Katis, V.L., Katou, Y., Mori, S., Itoh, T., Helmhart, W., Galova, M., Petronczki, M., Gregan, J., Cetin, B., et al. 2006. Protein phosphatase $2 \mathrm{~A}$ protects centromeric sister chromatid cohesion during meiosis I. Nature 441: 53-61.

Rieder, C.L. and Palazzo, R.E. 1992. Colcemid and the mitotic cycle. J. Cell Sci. 102: 387-392.

Ritchie, K., Seah, C., Moulin, J., Isaac, C., Dick, F., and Berube, N.G. 2008. Loss of ATRX leads to chromosome cohesion and congression defects. J. Cell Biol. 180: 315-324.

Rollins, R.A., Morcillo, P., and Dorsett, D. 1999. Nipped-B, a Drosophila homologue of chromosomal adherins, participates in activation by remote enhancers in the cut and Ultrabithorax genes. Genetics 152: 577-593.

Rollins, R.A., Korom, M., Aulner, N., Martens, A., and Dorsett, D. 2004. Drosophila nipped-B protein supports sister chromatid cohesion and opposes the stromalin/Scc3 cohesion factor to facilitate long-range activation of the cut gene. Mol. Cell. Biol. 24: 3100-3111.

Rubio, E.D., Reiss, D.J., Welcsh, P.L., Disteche, C.M., Filippova, G.N., Baliga, N.S., Aebersold, R., Ranish, J.A., and Krumm, A. 2008. CTCF physically links cohesin to chromatin. Proc. Nat1. Acad. Sci. 105: 8309-8314.

Ryu, M.J., Kim, B.J., Lee, J.W., Lee, M.W., Choi, H.K., and Kim, S.T. 2006. Direct interaction between cohesin complex and DNA replication machinery. Biochem. Biophys. Res. Commun. 341: 770-775.
Sakai, A., Hizume, K., Sutani, T., Takeyasu, K., and Yanagida, M. 2003. Condensin but not cohesin SMC heterodimer induces DNA reannealing through protein-protein assembly. EMBO J. 22: 2764-2775.

Salic, A., Waters, J.C., and Mitchison, T.J. 2004. Vertebrate shugoshin links sister centromere cohesion and kinetochore microtubule stability in mitosis. Cell 118: $567-578$.

Schleiffer, A., Kaitna, S., Maurer-Stroh, S., Glotzer, M., Nasmyth, K., and Eisenhaber, F. 2003. Kleisins: A superfamily of bacterial and eukaryotic SMC protein partners. Mol. Cell 11: 571-575.

Schmitz, J., Watrin, E., Lenart, P., Mechtler, K., and Peters, J.M. 2007. Sororin is required for stable binding of cohesin to chromatin and for sister chromatid cohesion in interphase. Curr. Biol. 17: 630-636.

Schuldiner, O., Berdnik, D., Levy, J.M., Wu, J.S., Luginbuhl, D., Gontang, A.C., and Luo, L. 2008. piggyBac-based mosaic screen identifies a postmitotic function for cohesin in regulating developmental axon pruning. Dev. Cell 14: 227-238.

Schule, B., Oviedo, A., Johnston, K., Pai, S., and Francke, U. 2005. Inactivating mutations in ESCO2 cause SC phocomelia and Roberts syndrome: No phenotype-genotype correlation. Am. J. Hum. Genet. 77: 1117-1128.

Seitan, V.C., Banks, P., Laval, S., Majid, N.A., Dorsett, D., Rana, A., Smith, J., Bateman, A., Krpic, S., Hostert, A., et al. 2006 Metazoan Scc4 homologs link sister chromatid cohesion to cell and axon migration guidance. PLOS Biol. 4: e242. doi 10.1371/journal.pbio.0040242.

Shimada, K. and Gasser, S.M. 2007. The origin recognition complex functions in sister-chromatid cohesion in Saccharomyces cerevisiae. Cell 128: 85-99.

Siomos, M.F., Badrinath, A., Pasierbek, P., Livingstone, D., White, J., Glotzer, M., and Nasmyth, K. 2001. Separase is required for chromosome segregation during meiosis I in Caenorhabditis elegans. Curr. Biol. 11: 1825-1835.

Sjogren, C. and Nasmyth, K. 2001. Sister chromatid cohesion is required for postreplicative double-strand break repair in Saccharomyces cerevisiae. Curr. Biol. 11: 991-995.

Skibbens, R.V. 2004. Chllp, a DNA helicase-like protein in budding yeast, functions in sister-chromatid cohesion. Genetics 166: $33-42$.

Skibbens, R.V., Corson, L.B., Koshland, D., and Hieter, P. 1999. Ctf7p is essential for sister chromatid cohesion and links mitotic chromosome structure to the DNA replication machinery. Genes \& Dev. 13: 307-319.

Sonoda, E., Matsusaka, T., Morrison, C., Vagnarelli, P., Hoshi, O., Ushiki, T., Nojima, K., Fukagawa, T., Waizenegger, I.C., Peters, J.M., et al. 2001. Scc1/Rad21/Mcd1 is required for sister chromatid cohesion and kinetochore function in vertebrate cells. Dev. Cell 1: 759-770.

Splinter, E., Heath, H., Kooren, J., Palstra, R.J., Klous, P., Grosveld, F., Galjart, N., and de Laat, W. 2006. CTCF mediates long-range chromatin looping and local histone modification in the $\beta$-globin locus. Genes \& Dev. 20: 2349-2354.

Stead, K., Aguilar, C., Hartman, T., Drexel, M., Meluh, P., and Guacci, V. 2003. Pds5p regulates the maintenance of sister chromatid cohesion and is sumoylated to promote the dissolution of cohesion. J. Cell Biol. 163: 729-741.

Stedman, W., Kang, H., Lin, S., Kissil, J.L., Bartolomei, M.S., and Lieberman, P.M. 2008. Cohesins localize with CTCF at the KSHV latency control region and at cellular c-myc and H19/ Igf2 insulators. EMBO I. 27: 654-666.

Stemmann, O., Zou, H., Gerber, S.A., Gygi, S.P., and Kirschner, M.W. 2001. Dual inhibition of sister chromatid separation at metaphase. Cell 107: 715-726.

Strom, L., Lindroos, H.B., Shirahige, K., and Sjogren, C. 2004. 
Postreplicative recruitment of cohesin to double-strand breaks is required for DNA repair. Mol. Cell 16: 1003-1015.

Strom, L., Karlsson, C., Lindroos, H.B., Wedahl, S., Katou, Y., Shirahige, K., and Sjogren, C. 2007. Postreplicative formation of cohesion is required for repair and induced by a single DNA break. Science 317: 242-245.

Strunnikov, A.V., Larionov, V.L., and Koshland, D. 1993. SMC1: An essential yeast gene encoding a putative head-rod-tail protein is required for nuclear division and defines a new ubiquitous protein family. J. Cell Biol. 123: 1635-1648.

Stursberg, S., Riwar, B., and Jessberger, R. 1999. Cloning and characterization of mammalian SMC1 and SMC3 genes and proteins, components of the DNA recombination complexes RC-1. Gene 228: 1-12.

Sumara, I., Vorlaufer, E., Gieffers, C., Peters, B.H., and Peters, J.M. 2000. Characterization of vertebrate cohesin complexes and their regulation in prophase. J. Cell Biol. 151: 749-761.

Sumara, I., Vorlaufer, E., Stukenberg, P.T., Kelm, O., Redemann, N., Nigg, E.A., and Peters, J.M. 2002. The dissociation of cohesin from chromosomes in prophase is regulated by polo-like kinase. Mol. Cell 9: 515-525.

Sundin, O. and Varshavsky, A. 1980. Terminal stages of SV40 DNA replication proceed via multiply intertwined catenated dimers. Cell 21: 103-114.

Suter, B., Tong, A., Chang, M., Yu, L., Brown, G.W., Boone, C., and Rine, J. 2004. The origin recognition complex links replication, sister chromatid cohesion and transcriptional silencing in Saccharomyces cerevisiae. Genetics 167: 579-591.

Takahashi, T.S., Yiu, P., Chou, M.F., Gygi, S., and Walter, J.C. 2004. Recruitment of Xenopus Scc2 and cohesin to chromatin requires the pre-replication complex. Nat. Cell Biol. 6: 991-996.

Takahashi, T.S., Basu, A., Bermudez, V., Hurwitz, J., and Walter, J.C. 2008. Cdc7-Drf1 kinase links chromosome cohesion to the initiation of DNA replication in Xenopus egg extracts. Genes \& Dev. 22: 1894-1905.

Takata, H., Matsunaga, S., Morimoto, A., Ma, N., Kurihara, D., Ono-Maniwa, R., Nakagawa, M., Azuma, T., Uchiyama, S., and Fukui, K. 2007. PHB2 protects sister-chromatid cohesion in mitosis. Curr. Biol. 17: 1356-1361.

Takeda, T., Ogino, K., Tatebayashi, K., Ikeda, H., Arai, K., and Masai, H. 2001. Regulation of initiation of S phase, replication checkpoint signaling, and maintenance of mitotic chromosome structures during $\mathrm{S}$ phase by Hsk1 kinase in the fission yeast. Mol. Biol. Cell 12: 1257-1274.

Tanaka, T., Cosma, M.P., Wirth, K., and Nasmyth, K. 1999. Identification of cohesin association sites at centromeres and along chromosome arms. Cell 98: 847-858.

Tanaka, T., Fuchs, J., Loidl, J., and Nasmyth, K. 2000. Cohesin ensures bipolar attachment of microtubules to sister centromeres and resists their precocious separation. Nat. Cell Biol. 2: 492-499.

Tanaka, K., Hao, Z., Kai, M., and Okayama, H. 2001. Establishment and maintenance of sister chromatid cohesion in fission yeast by a unique mechanism. EMBO J. 20: 5779-5790.

Tang, Z., Sun, Y., Harley, S.E., Zou, H., and Yu, H. 2004. Human Bub1 protects centromeric sister-chromatid cohesion through Shugoshin during mitosis. Proc. Natl. Acad. Sci. 101: 18012-18017.

Tang, Z., Shu, H., Qi, W., Mahmood, N.A., Mumby, M.C., and $\mathrm{Yu}, \mathrm{H} .2006$. PP2A is required for centromeric localization of Sgol and proper chromosome segregation. Dev. Cell 10: 575585.

Terret, M.E., Wassmann, K., Waizenegger, I., Maro, B., Peters, J.M., and Verlhac, M.H. 2003. The meiosis I-to-meiosis II transition in mouse oocytes requires separase activity. Curr. Biol. 13: 1797-1802.

Thein, K.H., Kleylein-Sohn, J., Nigg, E.A., and Gruneberg, U. 2007. Astrin is required for the maintenance of sister chromatid cohesion and centrosome integrity. J. Cell Biol. 178: 345-354.

Tomkins, D., Hunter, A., and Roberts, M. 1979. Cytogenetic findings in Roberts-SC phocomelia syndrome(s). Am. J. Med. Genet. 4: 17-26.

Tomonaga, T., Nagao, K., Kawasaki, Y., Furuya, K., Murakami, A., Morishita, J., Yuasa, T., Sutani, T., Kearsey, S.E., Uhlmann, F., et al. 2000. Characterization of fission yeast cohesin: Essential anaphase proteolysis of Rad21 phosphorylated in the S phase. Genes \& Dev. 14: 2757-2770.

Tonkin, E.T., Wang, T.J., Lisgo, S., Bamshad, M.J., and Strachan, T. 2004. NIPBL, encoding a homolog of fungal Scc2-type sister chromatid cohesion proteins and fly Nipped-B, is mutated in Cornelia de Lange syndrome. Nat. Genet. 36: 636641

Toth, A., Ciosk, R., Uhlmann, F., Galova, M., Schleiffer, A., and Nasmyth, K. 1999. Yeast cohesin complex requires a conserved protein, Ecolp(Ctf7), to establish cohesion between sister chromatids during DNA replication. Genes \& Dev. 13: 320-333.

Toyoda, Y. and Yanagida, M. 2006. Coordinated requirements of human topo II and cohesin for metaphase centromere alignment under Mad2-dependent spindle checkpoint surveillance. Mol. Biol. Cell 17: 2287-2302.

Uhlmann, F. and Nasmyth, K. 1998. Cohesion between sister chromatids must be established during DNA replication. Curr. Biol. 8: 1095-1101.

Uhlmann, F., Lottspeich, F., and Nasmyth, K. 1999. Sister-chromatid separation at anaphase onset is promoted by cleavage of the cohesin subunit Scc1. Nature 400: 37-42.

Uhlmann, F., Wernic, D., Poupart, M.A., Koonin, E.V., and Nasmyth, K. 2000. Cleavage of cohesin by the CD clan protease separin triggers anaphase in yeast. Cell 103: 375-386.

Unal, E., Arbel-Eden, A., Sattler, U., Shroff, R., Lichten, M., Haber, J.E., and Koshland, D. 2004. DNA damage response pathway uses histone modification to assemble a doublestrand break-specific cohesin domain. Mol. Cell 16: 991-1002.

Unal, E., Heidinger-Pauli, J.M., and Koshland, D. 2007. DNA double-strand breaks trigger genome-wide sister-chromatid cohesion through Ecol (Ctf7). Science 317: 245-248.

Unal, E., Heidinger-Pauli, J.M., Kim, W., Guacci, V., Onn, I., Gygi, S.P., and Koshland, D.E. 2008. A molecular determinant for the establishment of sister chromatid cohesion. Science 321: 566-569.

Vagnarelli, P., Morrison, C., Dodson, H., Sonoda, E., Takeda, S., and Earnshaw, W.C. 2004. Analysis of Scc1-deficient cells defines a key metaphase role of vertebrate cohesin in linking sister kinetochores. EMBO Rep. 5: 167-171.

Valdeolmillos, A., Rufas, J.S., Suja, J.A., Vass, S., Heck, M.M., Martinez, A.C., and Barbero, J.L. 2004. Drosophila cohesins DSA1 and Drad21 persist and colocalize along the centromeric heterochromatin during mitosis. Biol. Cell 96: 457462.

van Heemst, D., James, F., Poggeler, S., Berteaux-Lecellier, V., and Zickler, D. 1999. Spo76p is a conserved chromosome morphogenesis protein that links the mitotic and meiotic programs. Cell 98: 261-271.

Vass, S., Cotterill, S., Valdeolmillos, A.M., Barbero, J.L., Lin, E., Warren, W.D., and Heck, M.M. 2003. Depletion of Drad21/ Scc1 in Drosophila cells leads to instability of the cohesin complex and disruption of mitotic progression. Curr. Biol. 
13: $208-218$.

Vega, H., Waisfisz, Q., Gordillo, M., Sakai, N., Yanagihara, I., Yamada, M., van Gosliga, D., Kayserili, H., Xu, C., Ozono, $\mathrm{K}$. , et al. 2005. Roberts syndrome is caused by mutations in ESCO2, a human homolog of yeast ECO1 that is essential for the establishment of sister chromatid cohesion. Nat. Genet. 37: 468-470.

Venter, H., Shilling, R.A., Velamakanni, S., Balakrishnan, L., and Van Veen, H.W. 2003. An ABC transporter with a secondary-active multidrug translocator domain. Nature 426: 866-870.

Verni, F., Gandhi, R., Goldberg, M.L., and Gatti, M. 2000. Genetic and molecular analysis of wings apart-like (wapl), a gene controlling heterochromatin organization in Drosophila melanogaster. Genetics 154: 1693-1710.

Waizenegger, I.C., Hauf, S., Meinke, A., and Peters, J.M. 2000. Two distinct pathways remove mammalian cohesin from chromosome arms in prophase and from centromeres in anaphase. Cell 103: 399-410.

Waizenegger, I., Gimenez-Abian, J.F., Wernic, D., and Peters, J.M. 2002. Regulation of human separase by securin binding and autocleavage. Curr. Biol. 12: 1368-1378.

Wallace, J.A. and Felsenfeld, G. 2007. We gather together: Insulators and genome organization. Curr. Opin. Genet. Dev. 17: 400-407.

Wang, Z., Castaño, I.B., De Las Peñas, A., Adams, C., and Christman, M.F. 2000. Polк: A DNA polymerase required for sister chromatid cohesion. Sciene 289: 774-779.

Wang, F., Yoder, J., Antoshechkin, I., and Han, M. 2003. Caenorhabditis elegans EVL-14/PDS-5 and SCC-3 are essential for sister chromatid cohesion in meiosis and mitosis. Mol. Cell Biol. 23: 7698-7707.

Warren, W.D., Steffensen, S., Lin, E., Coelho, P., Loupart, M. Cobbe, N., Lee, J.Y., McKay, M.J., Orr-Weaver, T., Heck, M.M., et al. 2000. The Drosophila RAD21 cohesin persists at the centromere region in mitosis. Curr. Biol. 10: 1463-1466.

Warren, C.D., Eckley, D.M., Lee, M.S., Hanna, J.S., Hughes, A., Peyser, B., Jie, C., Irizarry, R., and Spencer, F.A. 2004. Sphase checkpoint genes safeguard high-fidelity sister chromatid cohesion. Mol. Biol. Cell 15: 1724-1735.

Watanabe, Y. 2004. Modifying sister chromatid cohesion for meiosis. J. Cell Sci. 117: 4017-4023.

Watanabe, Y. and Nurse, P. 1999. Cohesin Rec8 is required for reductional chromosome segregation at meiosis. Nature 400: $461-464$

Watanabe, Y., Yokobayashi, S., Yamamoto, M., and Nurse, P. 2001. Pre-meiotic S phase is linked to reductional chromosome segregation and recombination. Nature 409: 359-363.

Watrin, E. and Peters, J.M. 2006. Cohesin and DNA damage repair. Exp. Cell Res. 312: 2687-2693.

Watrin, E., Schleiffer, A., Tanaka, K., Eisenhaber, F., Nasmyth, K., and Peters, J.M. 2006. Human scc4 is required for cohesin binding to chromatin, sister-chromatid cohesion, and mitotic progression. Curr. Biol. 16: 863-874.

Weber, S.A., Gerton, J.L., Polancic, J.E., DeRisi, J.L., Koshland, D., and Megee, P.C. 2004. The kinetochore is an enhancer of pericentric cohesin binding. PLOS Biol. 2: E260. doi: 10.1371/ journal.pbio.0020260.

Weitzer, S., Lehane, C., and Uhlmann, F. 2003. A model for ATP hydrolysis-dependent binding of cohesin to DNA. Curr. Biol. 13: 1930-1940.

Wendt, K.S., Yoshida, K., Itoh, T., Bando, M., Koch, B., Schirghuber, E., Tsutsumi, S., Nagae, G., Ishihara, K., Mishiro, T., et al. 2008. Cohesin mediates transcriptional insulation by CCCTC-binding factor. Nature 451: 796-801.

Williams, B.C., Garrett-Engele, C.M., Li, Z., Williams, E.V.,
Rosenman, E.D., and Goldberg, M.L. 2003. Two putative acetyltransferases, san and deco, are required for establishing sister chromatid cohesion in Drosophila. Curr. Biol. 13: 2025-2036.

Wirth, K.G., Wutz, G., Kudo, N.R., Desdouets, C., Zetterberg, A., Taghybeeglu, S., Seznec, J., Ducos, G.M., Ricci, R., Firnberg, N., et al. 2006. Separase: A universal trigger for sister chromatid disjunction but not chromosome cycle progression. J. Cell Biol. 172: 847-860.

Wolstenholme, J. and Angell, R.R. 2000. Maternal age and trisomy-a unifying mechanism of formation. Chromosoma 109: 435-438.

Xu, H., Beasley, M.D., Warren, W.D., van der Horst, G.T., and McKay, M.J. 2005. Absence of mouse REC8 cohesin promotes synapsis of sister chromatids in meiosis. Dev. Cell 8: 949-961.

Yamagishi, Y., Sakuno, T., Shimura, M., and Watanabe, Y. 2008. Heterochromatin links to centromeric protection by recruiting shugoshin. Nature 455: 251-255.

Yamamoto, A., Guacci, V., and Koshland, D. 1996. Pdslp is required for faithful execution of anaphase in the yeast, Saccharomyces cerevisiae. J. Cell Biol. 133: 85-97.

Yazdi, P.T., Wang, Y., Zhao, S., Patel, N., Lee, E.Y., and Qin, J. 2002. SMC1 is a downstream effector in the ATM/NBS1 branch of the human S-phase checkpoint. Genes \& Dev. 16: $571-582$.

Yokobayashi, S. and Watanabe, Y. 2005. The kinetochore protein Moal enables cohesion-mediated monopolar attachment at meiosis I. Cell 123: 803-817.

Yoshimura, S.H., Hizume, K., Murakami, A., Sutani, T., Takeyasu, K., and Yanagida, M. 2002. Condensin architecture and interaction with DNA: Regulatory non-SMC subunits bind to the head of SMC heterodimer. Curr. Biol. 12: 508-513.

Zhang, B., Jain, S., Song, H., Fu, M., Heuckeroth, R.O., Erlich, J.M., Jay, P.Y., and Milbrandt, J. 2007. Mice lacking sister chromatid cohesion protein PDS5B exhibit developmental abnormalities reminiscent of Cornelia de Lange syndrome. Development 134: 3191-3201.

Zhang, J., Shi, X., Li, Y., Kim, B.J., Jia, J., Huang, Z., Yang, T., Fu, X., Jung, S.Y., Wang, Y., et al. 2008. Acetylation of Smc3 by Ecol is required for $S$ phase sister chromatid cohesion in both human and yeast. Mol. Cell 31: 143-151.

Zou, H., Stemman, O., Anderson, J.S., Mann, M., and Kirschner, M.W. 2002. Anaphase specific auto-cleavage of separase. FEBS Lett. 528: 246-250. 


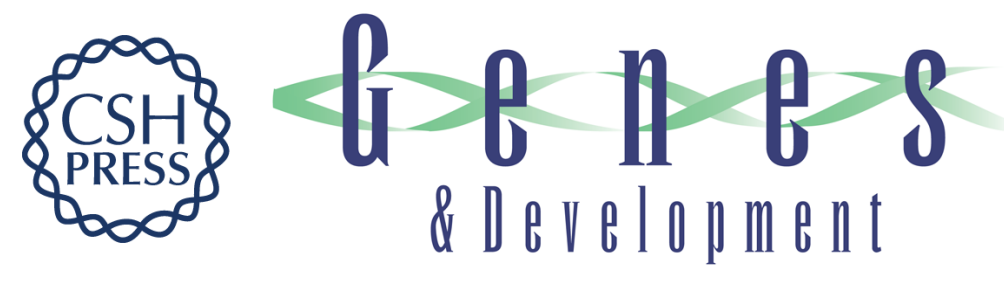

\section{The cohesin complex and its roles in chromosome biology}

Jan-Michael Peters, Antonio Tedeschi and Julia Schmitz

Genes Dev. 2008, 22:

Access the most recent version at doi:10.1101/gad.1724308

References This article cites 282 articles, 101 of which can be accessed free at: http://genesdev.cshlp.org/content/22/22/3089.full.html\#ref-list-1

License

Email Alerting Receive free email alerts when new articles cite this article - sign up in the box at the top Service right corner of the article or click here.

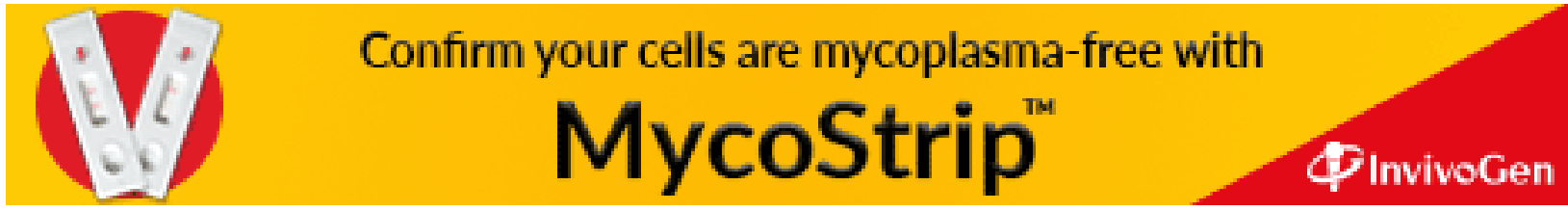

